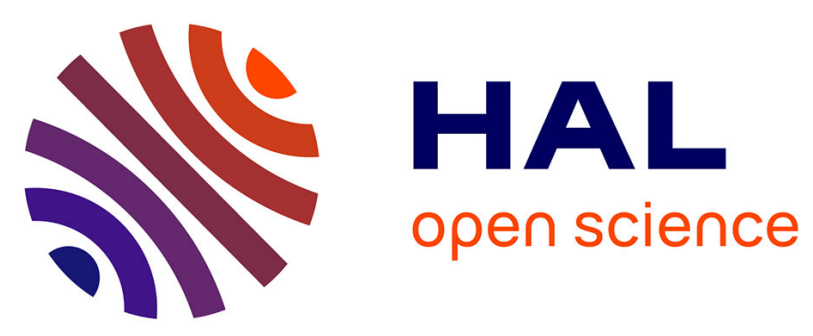

\title{
Impacts of pore- and petro-fabrics, mineral composition and diagenetic history on the bulk thermal conductivity of sandstones
}

Bassem S Nabawy, Yves Géraud

\section{- To cite this version:}

Bassem S Nabawy, Yves Géraud. Impacts of pore- and petro-fabrics, mineral composition and diagenetic history on the bulk thermal conductivity of sandstones. Journal of African Earth Sciences, 2016, 115, pp.48-62. 10.1016/j.jafrearsci.2015.11.025 . hal-02457299

\section{HAL Id: hal-02457299 \\ https://hal.univ-lorraine.fr/hal-02457299}

Submitted on 18 Oct 2020

HAL is a multi-disciplinary open access archive for the deposit and dissemination of scientific research documents, whether they are published or not. The documents may come from teaching and research institutions in France or abroad, or from public or private research centers.
L'archive ouverte pluridisciplinaire HAL, est destinée au dépôt et à la diffusion de documents scientifiques de niveau recherche, publiés ou non, émanant des établissements d'enseignement et de recherche français ou étrangers, des laboratoires publics ou privés.

\section{(1) (1) $\$$}

Distributed under a Creative Commons Attribution - NonCommercial - NoDerivatives 44.0 


\title{
Impacts of pore- and petro-fabrics, mineral composition and diagenetic history on the bulk thermal conductivity of sandstones
}

\author{
Bassem S. Nabawy ${ }^{\mathrm{a},{ }^{*}}$, Yves Ge raud $^{\mathrm{b}}$ \\ Department of Geophysical Sciences, National Research Centre, Cairo, Egypt \\ ${ }^{\mathrm{b}}$ Ecole Nationale Superieure de Geologie, Universite de Lorraine, Nancy, France
}

\begin{abstract}
The present study aims to model the bulk thermal fabric of the highly porous (26.5 øHesiliceous Nubia sandstones in south Egypt, as well as their pore- and petroanisotropy. The thermal fabric concept is used in the present study to describe the magnitude and direction of the thermal foliation ' $\mathrm{F}$ ', lineation ' $\mathrm{L}$ ' and anisotropy 'l'. Cementation, pressure solution, compaction and the authigenic clay content are the main pore volume-controlling factors, whereas the cement dissolution and fracturing are the most important porosity-enhancing factors.
\end{abstract}

The bulk thermal fabric of the Nubia sandstone is raised mostly from the contribution of the mineral composition and the pore volume. The kaolinite content and pore volume are the main reducing factors for the measured bulk thermal conductivity ' $\mathrm{k}$ ', whereas the quartz content is the most important enhancing factors. The optical

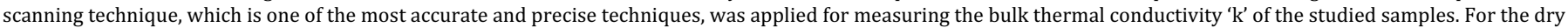
state, the average thermal condutivity ' $\mathrm{k}_{\mathrm{av}}$ ' in the NEeSW, NWeSE and vertical directions, varies from 1.53 to $2.40,1.54$ to 2.36 and from 1.31 to $2.20 \mathrm{~W} /$ (mK), respectively. On other hand, ' $\mathrm{k}_{\mathrm{av}}$ ' for the saline water-saturated state for the NEeSW, NWeSE and vertical directions varies between $2.94 \& 4.42,2.90 \& 4.31$ and between $2.39 \& 3.65$ $\mathrm{W} /(\mathrm{mK})$, respectively. The present thermal pore fabric is slightly anisotropic, 'l' varies from 1.10 to 1.41 , refers mostly to the NWeSE direction ( $\mathrm{k}_{\text {max }}$ direction, elongation direction), whereas the petro-fabric refers to NEeSW di- rection ( $\mathrm{k}_{\max }$ direction, elongation direction). This gives rise to a conclusion that the pore- and petro- fabrics have two different origins. Therefore, studying the thermal conductivity of the Nubia sandstone in 3-D indicates a pore fabric elongation fluctuating around the NeS direction.

Keywords: Bulk thermal conductivity, Pore fabric, Petro-fabric Mineral composition, Porosity

1. Introduction

To achieve a better understanding for the thermal flow mechanism in porous rocks and materials, the bulk thermal conductivity ' $\mathrm{k}$ ' has been studied theoretically and experimentally since many decades (e.g. Muskat, 1937; Blackwell, 1954, 1956). Recently, more attention has been paid for measuring ' $\mathrm{k}$ ' due to its new applications in geothermal energy production and storage. It is of great importance for predicting the heat flow from geothermal reservoirs

and for the thermal conductivity studies on rock materials.

A large set of techniques is available to measure the bulk thermal conductivity ' $\mathrm{k}$ ' parameter but it is a long time consuming to make a measurement.

The contactless tool for measuring ' $\mathrm{k}$ ', which applied to the present study, provides a good quality of the experimental data and modelling of the geothermal reservoirs (Popov et al., 2012). Measuring the bulk thermal conductivity using the optical scanning method can be run in a high speed, and has the advantage of measuring directly on the rock samples and its applications for the thermal anisotropy 'l' estimation (Popov et al., 1999).

The bulk thermal conductivity ' $\mathrm{k}$ ', is defined as "the quantity of heat ' $\mathrm{Q}$ ' transmitted through a thickness ' $\mathrm{L}$ ' in a direction normal to a surface of area ' $\mathrm{A}$ ' due to a temperature gradient ' $\mathrm{Dt}$ ', under steady state conditions". Assuming that the heat flow is dependent only on the temperature gradient, $\mathrm{k}$ could be calculates as follows:

Q L

$\mathrm{k} 1 / 4 *$

A Dt

It is also defined as "the ability of rock to conduct heat, measured in $\mathrm{W} /(\mathrm{mK})$, it could be calculated simply as follows.

Thermal properties of rocks are controlled by two sets of parameters, external parameters like pore fluid saturation, temperature and pressure, and internal parameters like mineral composition, pore volume and structures. In addition, density is present in the formulation of all the thermal parameters, and it is mostly controlled by two parameters, the mineral composition and the pore volume (McKenna et al., 1996; Maqsood and Kamran,

2005).

The authigenic clay content, as a common mineral composition, plays a main role in reducing the pore volume and closing the pore apertures (Bjørlykke et al., 1989). Pribnow and Umsonst (1993) calculated the bulk thermal conductivity of some crystalline rocks and indicated that the obtained values are mostly controlled by the quartz content.

Since porosity is a diagnostic property of sedimentary rocks, the pore volume and geometry are the key-control of the different physical properties, e.g. the bulk thermal conductivity (Lo et al., 1986; Tiab and Donaldson, 1996; Jones and Meredith, 1998; Rasolofosaon and Zinszner, 2002; Benson et al., 2005; Louis et al., 2005; etc...).

Porosity is mostly enhanced by some porosity-enhancing diagenetic factors, e.g. dissolution and leaching out of cement and grains, fracturing, weathering, and increasing or decreasing the rock volume, as well as some primary factors, e.g. grain sorting, sphericity and roundness (Nabawy and Kassab, 2014). On the other side, pore volume is reduced by cementation and precipitation from invasion by later solutions, re-crystallization, packing and compaction with depth and 
metamorphism (Bjørlykke, 1993, 1994; Bjorkum, 1996; Bjørlykke and Høeg, 1997). Porosity of the Nubia sandstone in south Egypt has been evolved as the net result of these enhancing and reducing factors which led to a complex pore fabric (Nabawy, 2013, 2014).

Taking into consideration the pore volume of a given rock, numerous theoretical \& empirical correlations and models have been introduced to estimate the thermal conductivity of its matrix from its bulk thermal conductivity (Progelhof et al., 1976; Fuchs et al., 2013).

A careful review of these models; however, indicates that no one correlation or technique accurately predicts the bulk thermal conductivity of all types of mixtures. So, the main target of the present study is to declare and model the impacts of the pore volume and mineral composition on the average bulk thermal conductivity ' $\mathrm{k}$ ' of the Nubia sandstone.

\section{Geologic setting and lithostratigraphy}

Nubia sandstone (Jurassic to Late Cretaceous) in SW Egypt are mainly composed of quartz arenite suffered from a long dry weather history. Their deposition was always topped by oolitic ironstone beds at the end of each depositional cycle. Therefore, the studied Nubia sandstone formations are characterized by intercalation of horizontal bedded thin oolitic ironstone beds ( $5 \mathrm{e} 15 \mathrm{~cm}$ thickness); sometimes found as laminas filling vertical and inclined fractures.

The arid weather that prevailed for a long time, fracturing, dissolution and leaching out of some of the ironstone beds may be the source of invasion of much iron-bearing solutions. This invasion offered some ferruginous quartz arenite beds in alternation with the quartz arenite in the Nubia sandstone sections.

Lithostratigraphy and classification of the Nubia sandstone $(250 \mathrm{~m})$ is still a matter of controversy; it is bare of fossils and similar in the mineral composition. It has been studied in its type sections by many workers, e.g. Said (1962), Issawi (1973), Klitzsch (1979), Hendriks (1988), Issawi and Osman (1993), etc.

The Nubia sandstone has been studied in the area located between Lat. 22150 e $22450 \mathrm{~N}$ and Long. 31000 e $31450 \mathrm{E}$ (Fig. 1) and can be summed up into four formations.

\subsection{Adindan formation (52.0 m, Jurassic-Valanginian)}

Its base is composed of $24 \mathrm{~m}$ of friable sandstone of greyish white to pale yellow highly fractured sandstone. Upwards, the Adindan Formation is composed of greyish white friable sandstone intercalated with highly fractured oolitic dark brown ironstone thin beds.

\subsection{Abu Simbel formation (120 m, Valanginian-Barremian)}

It conformably overlies the Adindan Formation. Its lower parts are composed of varicoloured mudstones intercalated with some friable sandstone beds followed upward by yellowish white friable sandstone. Upwards, its middle and top parts are composed of planar and tabular cross-bedded yellowish white to varicoloured friable sandstone.

\subsection{Abu Ballas formation (52.0 m, Aptian-Albian)}

Abu Ballas Formation is separated from the underlying Abu Simbel Formation by a regional thrust faulting. Its lower part (23.0 m) consists of reddish yellow, highly fractured, friable and blocky sandstone cross bedded at the base and pebbly upwards, intercalated with greyish coloured blocky mudstone and shales. Upwards, Abu Ballas Formation is composed of yellowish white cross bedded, coarse grained and conglomeratic sandstone intercalated and topped with thin beds of oolitic ironstone $(5 \mathrm{e} 15 \mathrm{~cm})$.

The Abu Ballas Formation have been controlled by a long history of tectonism which mostly increased the fracture porosity and the friability of the Nubia sandstone. This intensive tectonism has also greatly affected the oolitic ironstone beds in this area causing bending, lamination and mostly fracturing.

\subsection{Kesiena formation ( $26.0 \mathrm{~m}$, Campanian-Maastrichtian)}

It unconformably overlies the Abu Ballas Formation and disconformably overlain by the Paleocene Kurkur Formation. It is composed of greyish white to yellowish white, well bedded and friable sandstone. The middle part of Kesiena Formation is characterized by a greyish white phosphatic bed.

\section{Sampling, materials and methods}

A total of nineteen rock samples (fresh and not weathered) were selected representatively for the studied rock facies, and oriented horizontally to the magnetic north and vertically to the bedding plane. 
To reveal the mineral composition, a number of thin sections were prepared and examined under the polarized microscope. Nomenclature and classification of the studied samples were done following Pettijohn et al.'s, 1973 classification for sandstones. The studied thin sections were impregnated using blue dye for estimating the pore volume under the microscope using the point counting technique. Two thin sections, oriented vertical and parallel to the bedding plain, were prepared out of each sample which enable determining the pore volume in both directions. Nomenclature and classification of porosity has been done following Choquette and Pray's, 1970 classification.

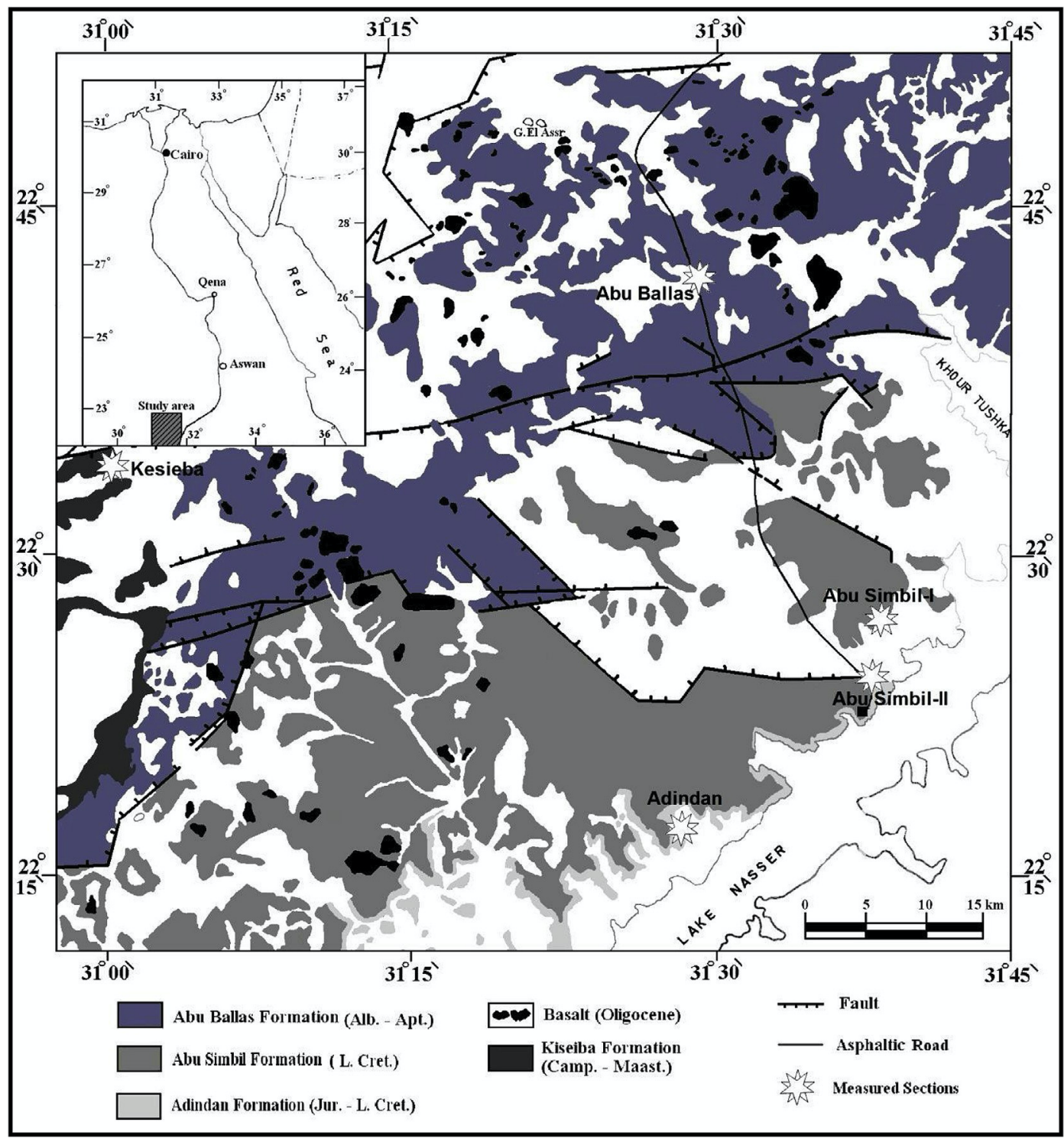

Fig. 1. A geological map for the studied Nubia sandstone in SW Egypt (Nabawy et al., 2009b).

In addition, other 19 rock samples were analyzed using a Philips X-ray Diffractometer (model D5000, anticathode Cu, $40 \mathrm{Kv}, 20 \mathrm{~mA}$ ). The XRD analysis was carried out initially on the bulk rock (crushed to size $<125 \mathrm{~mm}$ ) to determine the various mineral component, then on the fine fraction (less than $<2 \mathrm{~mm}$ ) for the identification of the various argillaceous content phases. Results are shown in Table 1.

The Scanning Electron Microscope 'SEM' supported with 'EDX' option was applied for identifying the pore- and petro-fabrics as well as types and distribution of secondary minerals, clay minerals in particular, and their impacts on the petrophysical characteristics of the studied rocks.

Prior to conducting the bulk thermal conductivity measurements, porosity and density of the rock samples were measured using two techniques; 1) helium injection at 19 psi pressure 'øн', and 2) water injection and full saturation at 0.001 bar vacuum pressure ' $\varnothing \mathrm{w}^{\prime}$. The applied techniques were described in details by Nabawy (2013, 2015) and Nabawy et al. (2009b, 2010, 2015).

The studied samples have been prepared as cubes ( $2 \mathrm{~cm}$ edge length) for measuring the thermal properties. The bulk thermal conductivity ' $\mathrm{k}$ ' was measured in both dry and saline water-saturated condition $(50 \mathrm{kppm}, \mathrm{NaCl})$ using the Thermal Conductivity Scanning (TCS) technique. TCS is a contactless optical scanning method derived by Popov $(1983,1984)$ to determine the bulk thermal conductivity. It yields a continuous profile of average thermal conductivity (e.g. Popov et al., 1999; Surma and Geraud, 2003 ).

The measurement has to be conducted in comparison with two standards of quartz composition have bulk thermal conductivity as close as possible to those of the scanned samples. 
With obtaining Dt of both the sample and the used standard as well as the known ' $\mathrm{k}$ ' of the standards $(\mathrm{k} 1 / 41.35 \mathrm{~W} /(\mathrm{mK}))$, ' $\mathrm{k}$ ' of the sample can be calculated as follows.

kstandard Dtsample

Ksample

Table 1

Relative

\begin{tabular}{|c|c|c|c|c|c|c|c|c|}
\hline $\mathrm{Fm}$ & S.No. & Quartz \% & Kaolinite \% & Calcite \% & Hematite \% & Goethite \% & Microcline \% & Gypsum \% \\
\hline \multirow[t]{3}{*}{ Kesiena Fm (26 m) } & 19 & 96.30 & 2.49 & 1.21 & $\mathrm{e}$ & e & $\mathrm{e}$ & e \\
\hline & 18 & 97.97 & 1.60 & 0.43 & e & e & e & e \\
\hline & 17 & 98.24 & 1.07 & 0.40 & e & e & e & 0.29 \\
\hline \multirow[t]{6}{*}{ Abu Ballas Fm (52 m) } & 16 & 90.28 & 6.79 & e & 1.05 & 1.88 & e & e \\
\hline & 15 & 89.73 & 3.01 & 2.26 & 2.34 & 1.02 & 1.64 & e \\
\hline & 14 & 98.71 & 1.29 & e & e & e & $\mathrm{e}$ & e \\
\hline & 13 & 97.58 & 1.11 & 1.31 & e & e & e & e \\
\hline & 12 & 93.68 & 5.92 & e & e & e & 0.40 & e \\
\hline & 11 & 99.45 & 0.55 & e & e & e & & e \\
\hline \multirow[t]{7}{*}{ Abu Simbel Fm (120 m) } & 10 & 95.50 & 4.04 & 0.18 & e & $\mathrm{e}$ & e & 0.28 \\
\hline & 9 & 93.76 & 5.13 & 0.45 & 0.66 & e & e & e \\
\hline & 8 & 95.98 & 1.60 & e & 1.47 & 0.95 & e & e \\
\hline & 7 & 97.20 & 2.44 & e & 0.36 & e & e & e \\
\hline & 6 & 99.52 & 0.35 & 0.13 & e & e & e & e \\
\hline & 5 & 99.35 & 0.48 & 0.17 & e & e & e & e \\
\hline & 4 & 99.50 & 0.50 & e & e & e & e & e \\
\hline \multirow[t]{6}{*}{ Adindan Fm (52 m) } & 3 & 91.77 & 3.52 & 0.75 & 1.40 & 2.56 & e & e \\
\hline & 2 & 98.99 & 0.73 & 0.28 & e & e & e & e \\
\hline & 1 & 98.97 & 1.03 & e & e & e & e & e \\
\hline & Min. & 89.73 & 0.35 & 0.13 & 0.36 & 0.95 & 0.40 & 0.28 \\
\hline & Max. & 99.52 & 6.79 & 2.26 & 2.34 & 2.56 & 1.64 & 0.29 \\
\hline & Mean & 96.45 & 2.30 & e & e & e & e & e \\
\hline
\end{tabular}

After the optical scanning is completed, the minimum, average and maximum bulk thermal conductivity of each single scanning direction has been obtained. Results of porosity (measured using helium and water injection), the bulk density and the thermal conductivity measured in the different directions are shown in Tables 2 and 3 .
(3)

\section{Proposed concept for the thermal pore- and petro-fabrics}

It is well understood that sedimentary structures of sedimentary rocks and schistosity or foliation of metamorphic materials develop anisotropy of physical properties with a difference between values measured through the planar structures, schistosity and foliation as well as along a perpendicular direction to theses

surfaces (Cermak and Rybach, 1982; Clauser and Huenges, 1995). The bulk thermal conductivity ' $\mathrm{k}$ ' of the present samples were

Table 2

Bulk thermal conductivity data and petro-fabric parameters of the studied samples in the dry state.

\begin{tabular}{|c|c|c|c|c|c|c|c|c|c|c|c|c|c|c|c|c|}
\hline \multirow[t]{2}{*}{ Fm } & \multirow[t]{2}{*}{ S.No. } & \multicolumn{3}{|c|}{ NEeSW } & \multicolumn{3}{|c|}{ NWeSE } & \multicolumn{3}{|c|}{ Vertical } & \multirow[t]{2}{*}{$\mathrm{k}_{\mathrm{av}}$} & \multicolumn{3}{|c|}{ Fabric parameters } & \multirow[t]{2}{*}{$\varnothing_{\mathrm{He}}$} & \multirow[t]{2}{*}{ sb } \\
\hline & & kav & $\mathrm{kmin}$ & $\mathrm{kmax}$ & kav & $\mathrm{kmin}$ & $\mathrm{kmax}$ & kav & $\mathrm{kmin}$ & $\mathrm{kmax}$ & & $\mathrm{F}$ & $\mathrm{L}$ & 1 & & \\
\hline \multirow[t]{3}{*}{ Kesiena Fm $(26 \mathrm{~m})$} & 19 & 1.71 & 1.62 & 1.77 & 1.73 & 1.53 & 1.83 & 1.46 & 1.38 & 1.54 & 1.63 & 1.17 & 1.01 & 1.01 & 26.5 & 2.00 \\
\hline & 18 & 2.37 & 2.25 & 2.47 & 2.25 & 2.16 & 2.31 & 1.96 & 1.88 & 2.03 & 2.19 & 1.15 & 1.06 & 1.21 & 27.8 & 2.19 \\
\hline & 17 & 2.40 & 2.26 & 2.53 & 2.35 & 2.26 & 2.46 & 2.20 & 2.07 & 2.30 & 2.32 & 1.07 & 1.02 & 1.10 & 27.1 & 2.16 \\
\hline
\end{tabular}




\begin{tabular}{|c|c|c|c|c|c|c|c|c|c|c|c|c|c|c|c|c|}
\hline \multirow[t]{6}{*}{ Abu Ballas Fm (52 m) } & 16 & 1.67 & 1.60 & 1.71 & 1.64 & 1.58 & 1.68 & 1.38 & 1.35 & 1.41 & 1.56 & 1.19 & 1.01 & 1.21 & 36.6 & 1.84 \\
\hline & 15 & 1.81 & 1.77 & 1.86 & 1.78 & 1.68 & 1.83 & 1.59 & 1.54 & 1.62 & 1.73 & 1.13 & 1.01 & 1.14 & 36.0 & 2.03 \\
\hline & 14 & 1.97 & 1.85 & 2.04 & 1.89 & 1.82 & 2.00 & 1.72 & 1.65 & 1.79 & 1.86 & 1.10 & 1.05 & 1.15 & 34.6 & 1.82 \\
\hline & 13 & 2.17 & 1.94 & 2.32 & 2.17 & 1.99 & 2.28 & 1.87 & 1.72 & 2.00 & 2.07 & 1.16 & 1.00 & 1.17 & 30.5 & 1.90 \\
\hline & 12 & 1.76 & 1.64 & 1.87 & 1.73 & 1.55 & 1.82 & 1.45 & 1.41 & 1.51 & 1.65 & 1.20 & 1.02 & 1.22 & 35.8 & 1.75 \\
\hline & 11 & 1.97 & 1.84 & 2.02 & 1.98 & 1.88 & 2.04 & 1.63 & 1.60 & 1.66 & 1.86 & 1.21 & 1.01 & 1.22 & 33.7 & 1.71 \\
\hline \multirow[t]{7}{*}{ Abu Simbel Fm (120 m) } & 10 & 1.97 & 1.80 & 2.06 & 2.02 & 1.92 & 2.09 & 1.65 & 1.61 & 1.72 & 1.88 & 1.19 & 1.03 & 1.22 & 33.5 & 1.66 \\
\hline & 9 & 2.12 & 2.00 & 2.27 & 2.05 & 1.98 & 2.15 & 1.88 & 1.81 & 1.94 & 2.02 & 1.09 & 1.03 & 1.13 & 29.6 & 2.02 \\
\hline & 8 & 1.81 & 1.72 & 1.88 & 1.78 & 1.67 & 1.85 & 1.57 & 1.56 & 1.60 & 1.72 & 1.13 & 1.02 & 1.15 & 36.5 & 1.87 \\
\hline & 7 & 2.17 & 2.00 & 2.30 & 2.36 & 2.25 & 2.45 & 1.97 & 1.93 & 2.00 & 2.17 & 1.10 & 1.09 & 1.20 & 29.2 & 2.05 \\
\hline & 6 & 1.66 & 1.55 & 1.73 & 1.55 & 1.48 & 1.59 & 1.47 & 1.44 & 1.50 & 1.56 & 1.06 & 1.07 & 1.13 & 39.0 & 1.74 \\
\hline & 5 & 2.14 & 1.99 & 2.22 & 2.11 & 2.02 & 2.18 & 1.87 & 1.81 & 1.90 & 2.04 & 1.13 & 1.01 & 1.14 & 33.5 & 1.83 \\
\hline & 4 & 1.84 & 1.76 & 1.91 & 1.79 & 1.69 & 1.87 & 1.65 & 1.59 & 1.71 & 1.76 & 1.09 & 1.03 & 1.12 & 38.0 & 1.68 \\
\hline \multirow[t]{7}{*}{ Adindan Fm (52 m) } & 3 & 2.17 & 2.04 & 2.25 & 2.13 & 1.99 & 2.24 & 1.90 & 1.84 & 1.94 & 2.07 & 1.12 & 1.02 & 1.14 & 28.9 & 2.04 \\
\hline & 2 & 1.54 & 1.49 & 1.59 & 1.54 & 1.45 & 1.58 & 1.31 & 1.19 & 1.41 & 1.46 & 1.04 & 1.00 & 1.04 & 38.1 & 1.86 \\
\hline & 1 & 1.76 & 1.68 & 1.81 & 1.74 & 1.70 & 1.77 & 1.50 & 1.47 & 1.53 & 1.67 & 1.16 & 1.01 & 1.17 & 38.8 & 1.82 \\
\hline & Min. & 1.54 & 1.49 & 1.59 & 1.54 & 1.45 & 1.58 & 1.31 & 1.19 & 1.41 & 1.46 & 1.06 & 1.00 & 1.01 & 26.5 & 1.66 \\
\hline & Max. & 2.40 & 2.26 & 2.53 & 2.36 & 2.26 & 2.46 & 2.20 & 2.07 & 2.30 & 2.32 & 1.21 & 1.09 & 1.22 & 39.0 & 2.19 \\
\hline & Mean & 1.95 & 1.83 & 2.03 & 1.93 & 1.82 & 2.00 & 1.68 & 1.62 & 1.74 & 1.85 & 1.14 & 1.03 & 1.17 & 33.7 & 1.89 \\
\hline & St. dv. & 0.27 & 0.24 & 0.29 & 0.27 & 0.27 & 0.29 & 0.26 & 0.25 & 0.27 & 0.26 & 0.05 & 0.03 & 0.05 & 4.20 & 0.16 \\
\hline
\end{tabular}

Notes: $\mathrm{k}_{\mathrm{av}}, \mathrm{k}_{\min }$ and $\mathrm{k}_{\max }$; are the average, minimum and maximum thermal conductivity for the measured profile; respectively, in $\mathrm{W} /(\mathrm{mK})$.

$\mathrm{k}_{\mathrm{av}} \mathrm{O}$, is the average bulk thermal conductivity for the different profiles of each sample, in $\mathrm{W} /(\mathrm{mK}) . \emptyset_{\mathrm{He}}$, is the

helium porosity, in \%. Sb, is the bulk density, in $\mathrm{g} / \mathrm{cm}^{3}$.

$\mathrm{L}$, is the thermal lineation, in $0.00 . \mathrm{F}$, is

thermal foliation, in 0.00 , and. I, is the

thermal anisotropy, in 0.00 .

Table 3

Bulk thermal conductivity data and thermal fabric parameters of the studied sandstone samples in the saline-saturated state.

\begin{tabular}{|c|c|c|c|c|c|c|c|c|c|c|c|c|c|c|c|}
\hline \multirow[t]{2}{*}{ Fm } & \multirow[t]{2}{*}{ S.No. } & \multicolumn{3}{|c|}{ NEeSW } & \multicolumn{3}{|c|}{ NWeSE } & \multicolumn{3}{|c|}{ Vertical } & \multirow[t]{2}{*}{$\mathrm{k}_{\mathrm{av}}$} & \multicolumn{3}{|c|}{ Fabric parameters } & \multirow[t]{2}{*}{$\varnothing_{\mathrm{W}}$} \\
\hline & & kav & kmin & kmax & kav & kmin & kmax & kav & $\mathrm{kmin}$ & kmax & & $\mathrm{F}$ & $\mathrm{L}$ & I & \\
\hline \multirow[t]{3}{*}{ Kesiena Fm (26 m) } & 19 & 3.31 & 2.89 & 3.52 & 3.78 & 3.30 & 4.01 & 3.18 & 3.01 & 3.49 & 3.42 & 1.04 & 1.00 & 1.02 & 22.5 \\
\hline & 18 & 4.18 & 3.82 & 4.38 & 3.87 & 3.60 & 4.06 & 3.21 & 3.05 & 3.42 & 3.75 & 1.20 & 1.08 & 1.30 & 21.9 \\
\hline & 17 & 3.77 & 3.34 & 4.05 & 3.88 & 3.80 & 3.99 & 3.65 & 3.38 & 4.21 & 3.80 & 1.15 & 1.08 & 1.11 & 23.6 \\
\hline \multirow[t]{6}{*}{ Abu Ballas Fm (52 m) } & 16 & 2.94 & 2.75 & 3.10 & 2.90 & 2.73 & 3.06 & 2.39 & 2.30 & 2.49 & 2.74 & 1.14 & 1.08 & 1.11 & 29.5 \\
\hline & 15 & 3.17 & 3.01 & 3.31 & 3.22 & 3.08 & 3.36 & 2.83 & 2.53 & 3.04 & 3.07 & 1.12 & 1.02 & 1.14 & 28.9 \\
\hline & 14 & 3.72 & 3.44 & 4.01 & 3.65 & 3.50 & 3.93 & 2.92 & 2.80 & 3.03 & 3.43 & 1.25 & 1.02 & 1.27 & 26.4 \\
\hline & 13 & 3.77 & 3.55 & 3.98 & 3.92 & 3.56 & 4.16 & 3.28 & 2.99 & 3.50 & 3.66 & 1.15 & 1.04 & 1.20 & 27.5 \\
\hline & 12 & 3.15 & 2.91 & 3.24 & 3.17 & 2.90 & 3.36 & 2.69 & 2.50 & 2.87 & 3.00 & 1.17 & 1.01 & 1.18 & 28.4 \\
\hline & 11 & 3.51 & 3.35 & 3.72 & 3.45 & 3.32 & 3.57 & 3.53 & 3.15 & 3.83 & 3.50 & 1.01 & 1.01 & 1.01 & 28.0 \\
\hline \multirow[t]{5}{*}{ Abu Simbel Fm (120 m) } & 10 & 3.15 & 2.82 & 3.40 & 3.38 & 2.96 & 3.47 & 3.15 & 3.04 & 3.43 & 3.23 & 1.03 & 1.01 & 1.04 & 30.9 \\
\hline & 9 & 3.22 & 3.00 & 3.38 & 3.25 & 3.12 & 3.42 & 3.00 & 2.83 & 3.34 & 3.16 & 1.04 & 1.01 & 1.05 & 26.9 \\
\hline & 8 & 3.13 & 2.79 & 3.32 & 3.23 & 2.91 & 3.34 & 3.46 & 3.21 & 3.58 & 3.28 & 1.03 & 1.07 & 1.10 & 29.6 \\
\hline & 7 & 3.92 & 3.67 & 4.20 & 3.92 & 3.78 & 4.15 & 3.01 & 2.82 & 3.36 & 3.62 & 1.30 & 1.08 & 1.41 & 22.3 \\
\hline & 6 & 3.54 & 3.33 & 3.66 & 3.34 & 3.21 & 3.43 & 2.91 & 2.78 & 3.18 & 3.26 & 1.14 & 1.06 & 1.22 & 27.9 \\
\hline
\end{tabular}




\begin{tabular}{|c|c|c|c|c|c|c|c|c|c|c|c|c|c|c|c|}
\hline & 5 & 4.42 & 4.14 & 4.64 & 4.31 & 4.13 & 4.61 & 3.34 & 3.13 & 3.41 & 4.03 & 1.33 & 1.03 & 1.36 & 21.9 \\
\hline & 4 & 3.58 & 3.42 & 3.88 & 3.77 & 3.60 & 3.97 & 2.96 & 2.75 & 3.36 & 3.44 & 1.21 & 1.05 & 1.27 & 26.7 \\
\hline \multirow[t]{7}{*}{ Adindan Fm (52 m) } & 3 & 3.49 & 3.32 & 3.64 & 3.48 & 3.37 & 3.75 & 3.04 & 2.82 & 3.23 & 3.33 & 1.15 & 1.03 & 1.18 & 23.9 \\
\hline & 2 & 3.53 & 3.41 & 3.62 & 3.46 & 3.25 & 3.62 & 3.01 & 2.73 & 3.20 & 3.33 & 1.15 & 1.02 & 1.17 & 28.4 \\
\hline & 1 & 3.31 & 3.19 & 3.52 & 3.41 & 3.28 & 3.50 & 3.09 & 2.82 & 3.29 & 3.27 & 1.07 & 1.03 & 1.05 & 27.8 \\
\hline & Min. & 2.94 & 2.75 & 3.10 & 2.90 & 2.73 & 3.06 & 2.39 & 2.30 & 2.49 & 2.74 & 1.00 & 1.00 & 1.01 & 21.9 \\
\hline & Max. & 4.42 & 4.14 & 4.64 & 4.31 & 4.13 & 4.61 & 3.65 & 3.38 & 4.21 & 4.03 & 1.33 & 1.08 & 1.41 & 30.9 \\
\hline & Mean & 3.52 & 3.27 & 3.71 & 3.56 & 3.34 & 3.75 & 3.10 & 2.88 & 3.33 & 3.39 & 1.13 & 1.03 & 1.16 & 26.2 \\
\hline & St. dv. & 0.38 & 0.37 & 0.41 & 0.35 & 0.36 & 0.39 & 0.30 & 0.26 & 0.36 & 0.30 & 0.09 & 0.03 & 0.12 & 2.88 \\
\hline
\end{tabular}

Notes: $\varnothing_{W}$, is the water porosity; other denotations as in Table 2.

studied in three perpendicular directions; in the vertical direction perpendicular to the bedding plain, and in other two directions oriented horizontally; one along the pore elongation and the other one is normal to the pore elongation. The pore elongation of the studied samples has been referred mostly as NEeSW directed for Abu Simbel Formation and referred to NWeSE for both Adindan and Kesiena Formations (Nabawy et al., 2009b). Therefore, three thermal profiles are obtained for each sample, in the vertical directions and in both NEeSW and NWeSE directions.

The maximum bulk thermal conductivity, $\mathrm{k}_{\max }$, the average, $\mathrm{k}_{\mathrm{av}}$, and the minimum one, $\mathrm{k}_{\min }$ for each profile have been used for calculating the bulk thermal anisotropy.

We selected the $\mathrm{k}_{\mathrm{av}}$ for each profile of each sample, arranged in ascending order, and referred as $\mathrm{k}_{\min }$, $\mathrm{k}_{\mathrm{int}}$. and $\mathrm{k}_{\max }$. These three values of ' $\mathrm{k}$ ' can be expressed as magnitudes of axes of 3-D ellipsoid

(Fig. 2).

Therefore, taking into consideration the concept of ellipsoid for ' $\mathrm{k}$ ' data; the following concepts should be proposed.

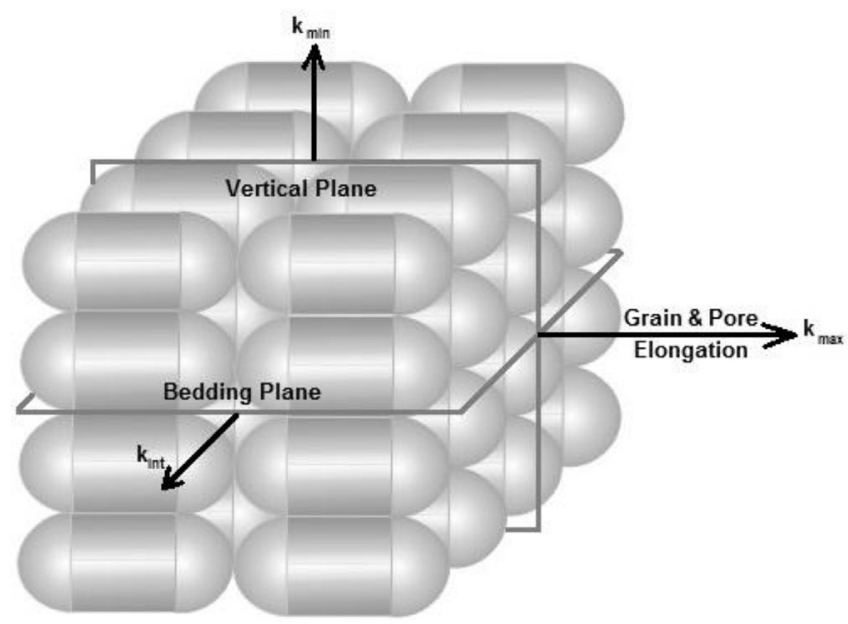

Fig. 2. Thermal conductivity ' $\mathrm{k}$ ' data measured in 3-D could be simulated as a group of ellipsoids oriented according to the pore elongation and the bedding plane.

*Thermal Lineation, $\mathrm{L}$, is defined as "the ratio between the maximum and average bulk thermal conductivity"

$\mathrm{L} 1 / 4 \mathrm{kmax}=\mathrm{kav}$

(4)

* Thermal Foliation, $\mathrm{F}$, is a defined as "the ratio between the average and the minimum bulk thermal conductivity"

$\mathrm{F} 1 / 4 \mathrm{kav}=\mathrm{kmin}$

* Thermal Anisotropy, I, is defined as "the ratio of the parallel 'kmax' and perpendicular 'kmin' components (to the bedding plane, foliation, schistosity, cracks or fractures) of the bulk thermal conductivity" (Cermak and Rybach, 1982).

$1 \frac{1}{4} \mathrm{kmax}=\mathrm{kmin}$ 


\section{Results}

\subsection{Mineral composition}

5.1.1. X-ray diffraction (XRD) studies

Prior to the petrographical studies, XRD studies were recommended to be conducted giving up an overall idea about the mineral composition of the studied rocks. According to the XRD studies, the Nubia samples are composed mainly of quartz as a main constituent (av. 96.5\%) beside to some kaolinite as a minor constituent (av. 2.8\%) (Table 1, Fig. 4) as well as some trace minerals represented by calcite, goethite and hematite. Rare microcline (av. 1.0\%) was noticed in Abu Ballas samples beside to some rare gypsum in Kesiena Formation (av. 0.29\%).

\subsubsection{Petrography}

The Nubia Sandstone consists of two main microfacies; quartz arenite and ferruginous quartz arenite.

\section{1) Quartz Arenite}




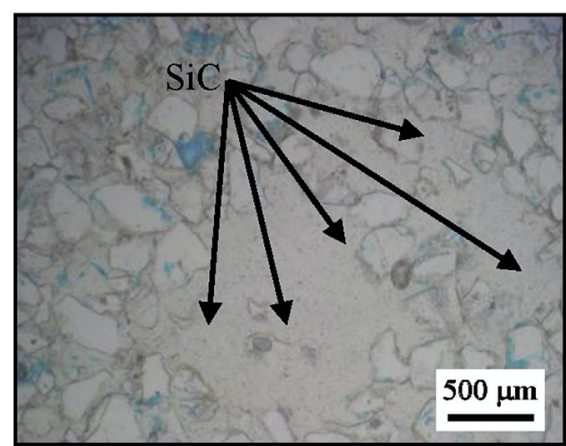

(A)

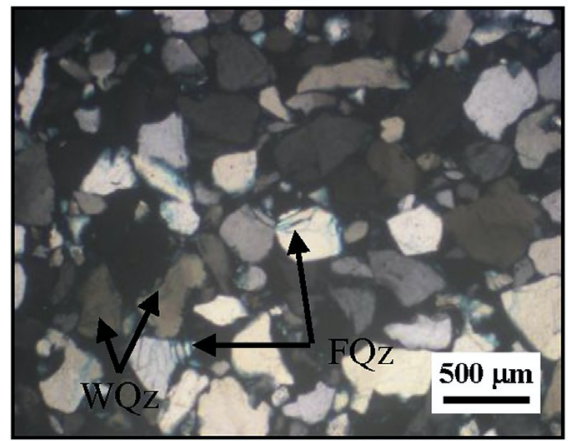

(C)

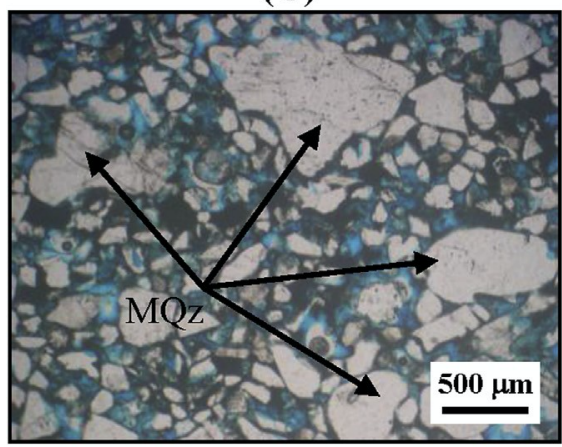

(E)

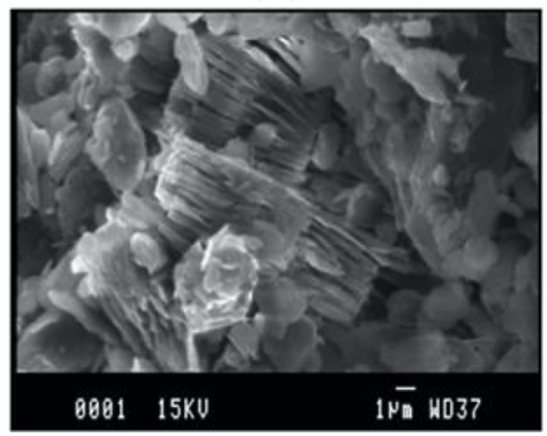

(G)

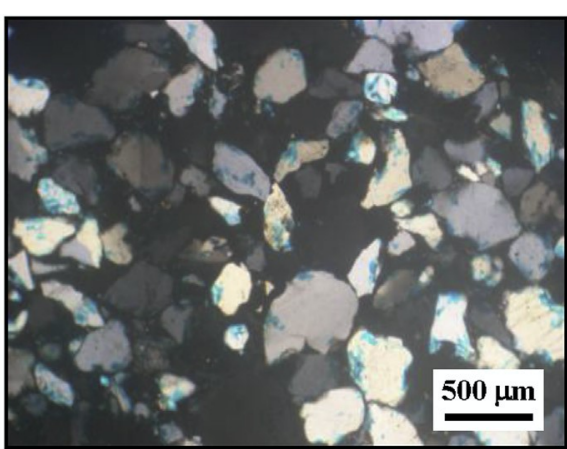

(B)

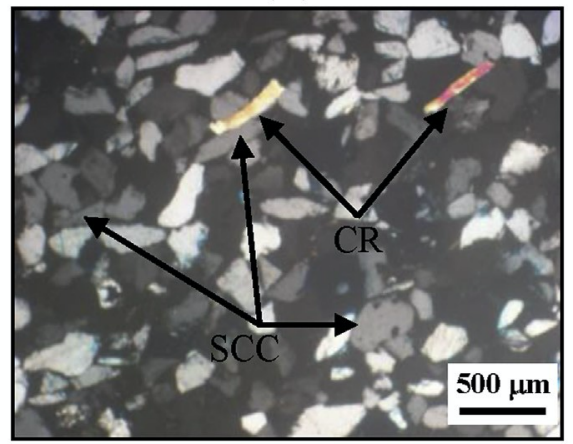

(D)

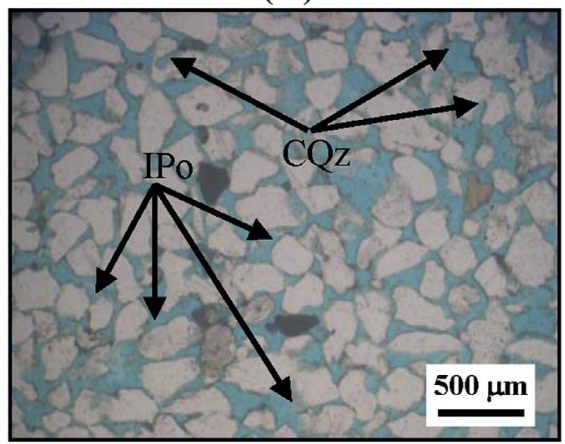

(F)

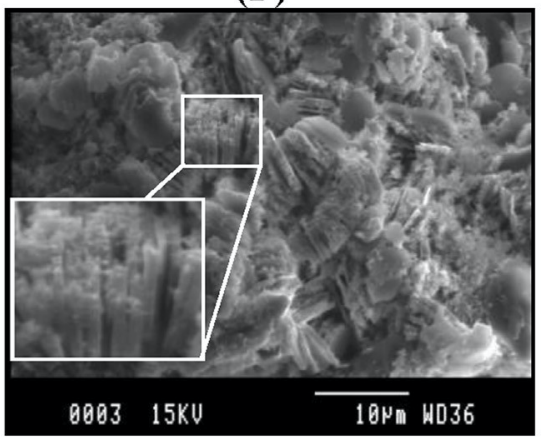

(H)

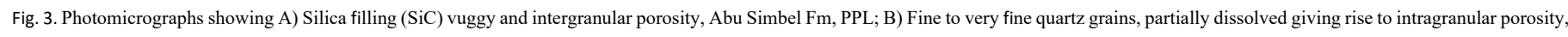

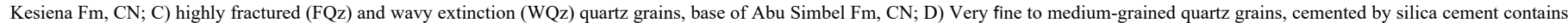

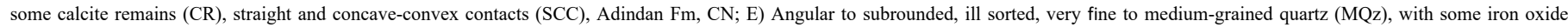

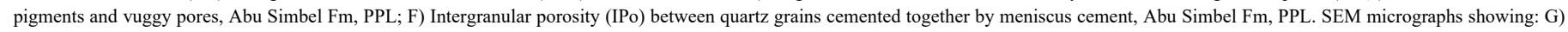
Kaolinite booklets reducing and blocking the pore channels, middle parts of Kesiena Fm, and H) Tiny iron oxide grains and filaments attached on some dickite booklets, top of Abu Ballas Fm.

It consists of ill-sorted fine to very fine, medium-grained, meniscus cement (Fig. 3A) in Adindan and Abu Simbel Formations. angular to sub-rounded quartz grains cemented by silica It is pebbly upward through the Abu Ballas and Kesiena Formations. 

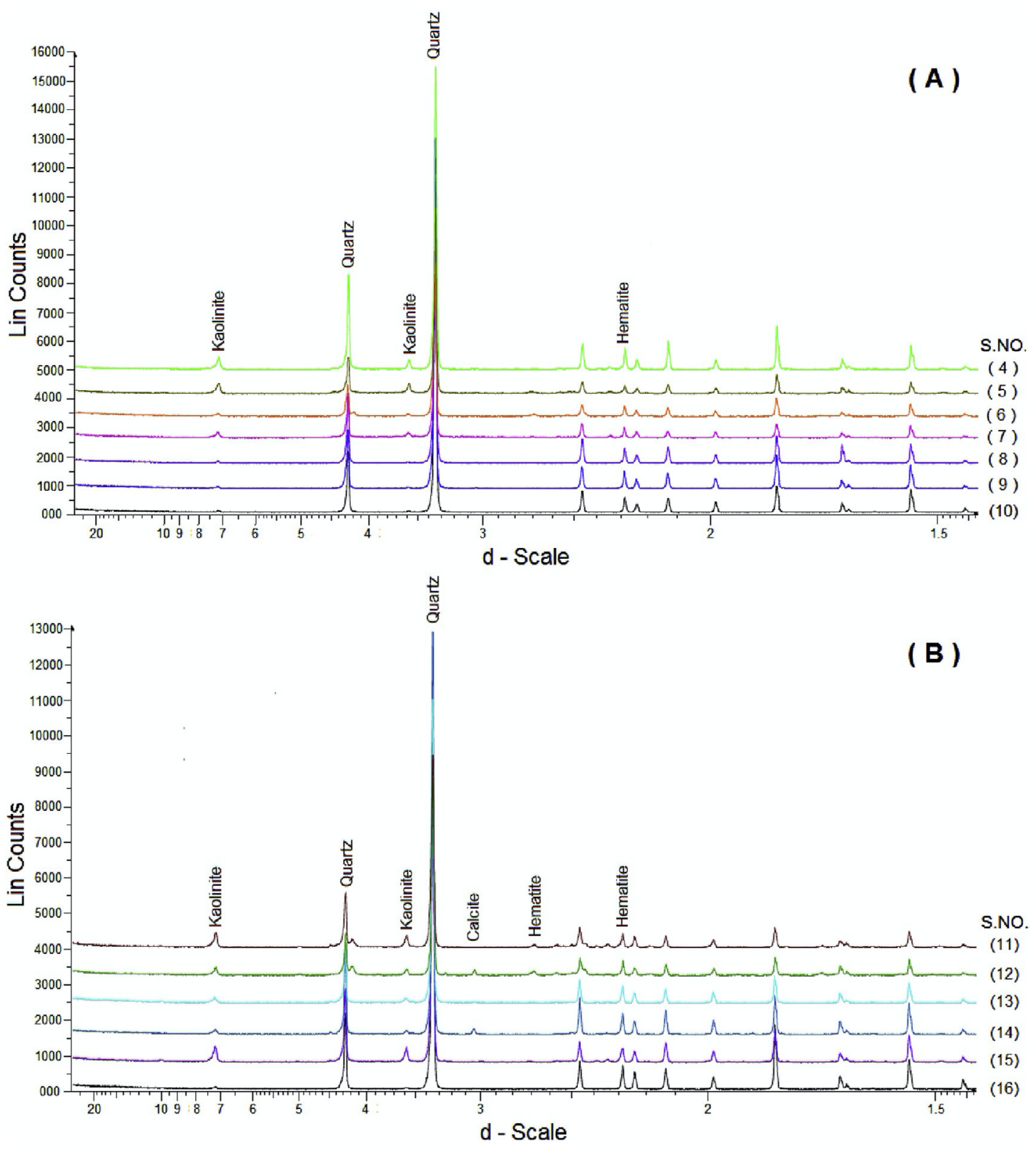

Fig. 4. X-Ray diagrams of the bulk samples of the Nubia sandstone: A) Abu Simbel samples, and B) Abu Ballas samples.

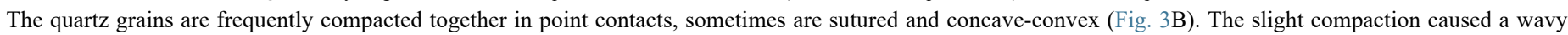
extinction for some quartz grains (Fig. 3C). Calcareous shell fragments are rarely present (Fig. 3D).

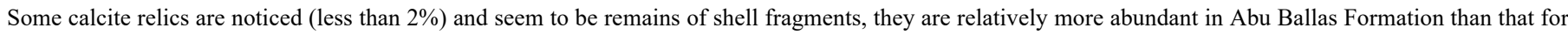

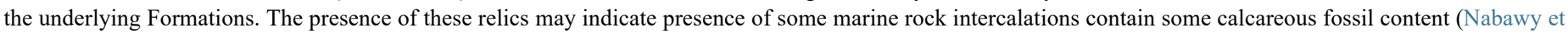
al., 2009b).

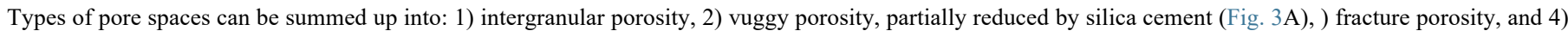
intragranular porosity.

\section{2) Ferruginous Quartz Arenite}

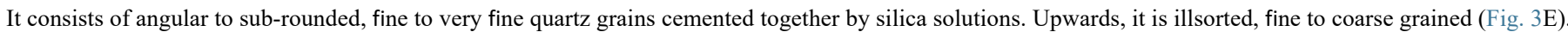
Patches of iron oxide grains are scattered within the cement and the pore channels; sometimes are attached to the grain surfaces.

The pore spaces are represented mainly by: 1) intergranular porosity, 2) intragranular porosity, and 3) vuggy porosity sometimes are filled with iron oxides.

The porosity values of both the quartz arenite and the ferruginous quartz arenite of the Nubia sandstone samples, in general, are very good; it is estimated to

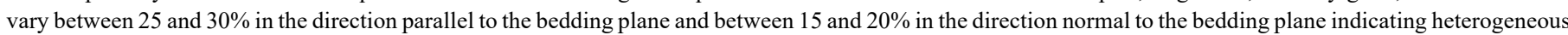
distribution for the pore spaces. 


\subsubsection{SEM studies}

The pore volume of the studied rock samples was mostly reduced by kaolinite booklets filling in the pore channels (Fig. 3G), sometimes are embedded within the cement.

Some tiny hematite grains and sometimes goethite are attached at the surfaces of the kaolinite booklets. The clay content also increases upwards in Abu Ballas and top Abu Simbel Formations and still represented by kaolinite booklets filling in the fluid pathways. The iron oxides are composed mainly of hematite, sometimes of goethite (Table 1). The hematite content increases and found as tiny grains sometimes as filaments-like shape (Fig. 3H).

\subsection{Diagenesis}

It is more favourable to distinguish the diagenetic processes based on their impacts on porosity into reducing and enhancing factors (Nabawy and Kassab, 2014). Porosity is mostly reduced by; 1) the compaction and pressure solution, 2) amount and distribution of authigenic minerals, and 3) cementation. On contrary, 1) fracturing, and 2) cement dissolution and leaching out, are the most important porosity-enhancing factors.

\subsubsection{Porosity-reducing diagenetic processes}

1) Compaction and pressure solution

Increasing the load pressure with depth causes compaction of the hard grains as well as fracturing and bending of the brittle ones. The degree of compaction may be strongly inhibited and diminished by early cementation by carbonate cement.

The tectonic regime of the Nubia sandstone was implied by a set of intersecting NW, NE and EeW structural trends giving rise to vertical and inclined joints and fractures which may be accompanied with the tectonic movements responsible for opening the red sea. The compaction effect on the studied microfacies can be stated by presence of many fractured quartz grains as in most of the studied horizons giving rise to what like exhausted quartz grains. Also, many quartz grains of wavy extinction (Fig. 3C) are assigned in Adindan, Abu Simbel and Abu Ballas formations.

\section{2) Authigenic minerals}

From the SEM and XRD studies, the authigenic minerals in the Nubia sandstones are mostly represented by kaolinite, hematite minerals and goethite (Figs. 3 and 4).

On the micro scale, the authigenic hematite and goethite (2.80\%) are represented by a pigment masking the quartz grains (Fig. $3 \mathrm{E})$. In other cases, it is represented by mud-sized grains disseminated within the cement and/or attached at the quartz grains (Fig. 3F).

The authigenic clay minerals (2.28\%) are represented mostly by booklets of kaolinite precipitated in the pore network and channels by some fluids invading the different formations, e.g. in Adindan, Abu Ballas (Fig. 3H) and Kesiena samples (Fig. 3G).

\section{3) Cementation}

Cementation by silica cement is the main porosity-reducing diagenetic process in the Nubia sandstone. The source of this silica may be attributed to dissolution and transformation of feldspars into kaolinite as well as pressure solution (Bjørlykke, 1983; Bjørlykke et al., 1989; Bjorkum et al., 1993). It is represented by silica cement filling the pore spaces, sometimes recrystallized to micro quartz. The silica cement in the Nubia sandstone samples are mostly present as meniscus cement (Fig. 3F) and filling the pore spaces and vugs (Fig. 3: A, B, C, D).

The cementation is slight and not uniform through the bulk rock volume giving rise to anisotropy in the petrophysical properties between the vertical and horizontal directions.

5.2.2. Porosity-enhancing diagenetic processes

\section{1) Fracturing}

Fracturing is a common feature for the Nubia sandstone in SW Egypt on both the field and micro scale. On the field scale, a fracture system is assigned filled with some iron oxide lamina caused by the invasion of iron-bearing solutions into the sandstone beds. On the micro scale, the Nubia sandstone is composed of highly cracked, fine to medium grained quartz grains (Fig. 3E) and sometimes have wavy extinction. This is in accordance with that stated by Nabawy et al. (2010), who studied the permeability of the Nubia sandstone. They assigned a vertical permeable fracture system responsible for increasing the permeability in the vertical directions.

\section{2) Dissolution and leaching out}

In the present study, a dissolution and leaching out of the original cement by solutions resulted in excellent porosity values $(\varnothing>25 \%)$, mostly represented by intergranular, fracture porosity and vuggy porosity. Movement of these solutions is indicated at the field scale by filling the vertical fractures by ironstone sheets due to dissolution of the oolitic ironstone beds. It is worth mentioned that, the vertical joints and fractures played an effective role in getting the flowing water into the different levels of the studied sandstone samples to activate the different chemical and physical weathering processes.

\subsubsection{Diagenetic sequence}

The diagenetic sequence is a very complex task due to the large number of diagenetic processes. However, the revealed diagenetic sequence of the studied samples could be listed as follows.

1) Deposition of quartz grains and feldspars.

2) Cementing the grains together probably by calcite cement, where some marine environments were detected by many workers (Bhattacharyya, 1989). 
3) Fracturing followed by invasion of solutions to dissolve and leach out the feldspars, shell fragments and the original cement.

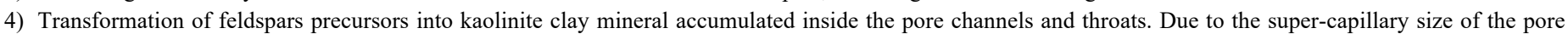
spaces (Nabawy et al., 2009a), most of this clay content may be leached out later.

5) Second phase of cementation by silica cement filling as meniscus cement and sometimes filling vugs (Fig. 3A).

5.3. Bulk thermal conductivity

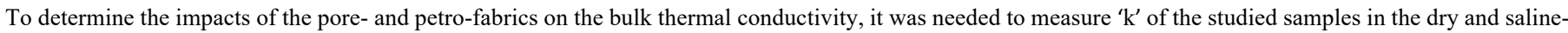
saturated states.

\subsubsection{Dry state}

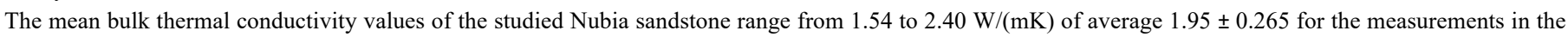

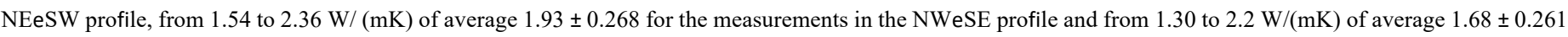
for the measurements in the vertical profile (Table 2).

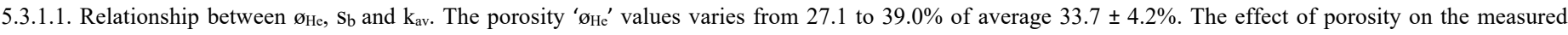

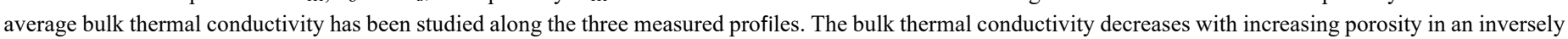
proportional relationship (Fig. 5A).

Processing the overall data obtained for the different profiles gave up an equation applicable for the bulk samples in the different profiles as follows:

$\mathrm{k}_{\mathrm{av}} 1 / 4 \mathrm{a} \quad \mathrm{b} \emptyset_{\mathrm{He}}$ đr $1 / 40: 923 \pm 0: 017 \mathrm{p}$

Where, $\mathrm{k}_{\mathrm{av}}$ is the average bulk thermal conductivity for the different profiles of each sample,

a is a constant value equals to $3.82 \pm 0.249$, and $\mathrm{b}$ is a multiplication factor equals to $0.058 \pm 0.0026$.

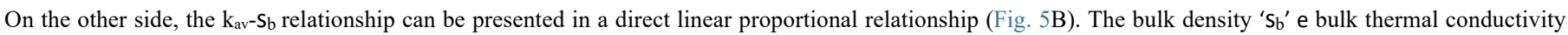
relationship for the dry sandstone samples can be presented by the following empirical equation

$\mathrm{k}_{\mathrm{av}} 1 / 4 \mathrm{as}$ b đr $1 / 40: 72 \pm 0: 017 \mathrm{p}$

Where, $\mathrm{a}$ is a multiplication factor equals to $1.26 \pm 0.072$, and $\mathrm{b}$ is a constant equals to $0.54 \pm 0.056$.

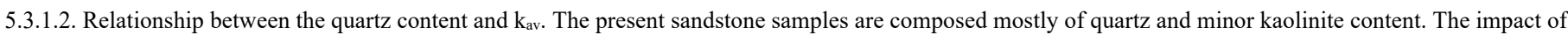

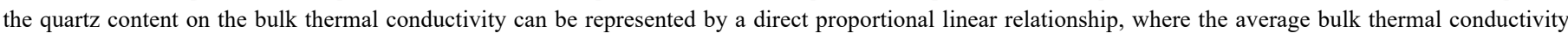
increases with increasing quartz content (Fig. 6A). It can be pre- 


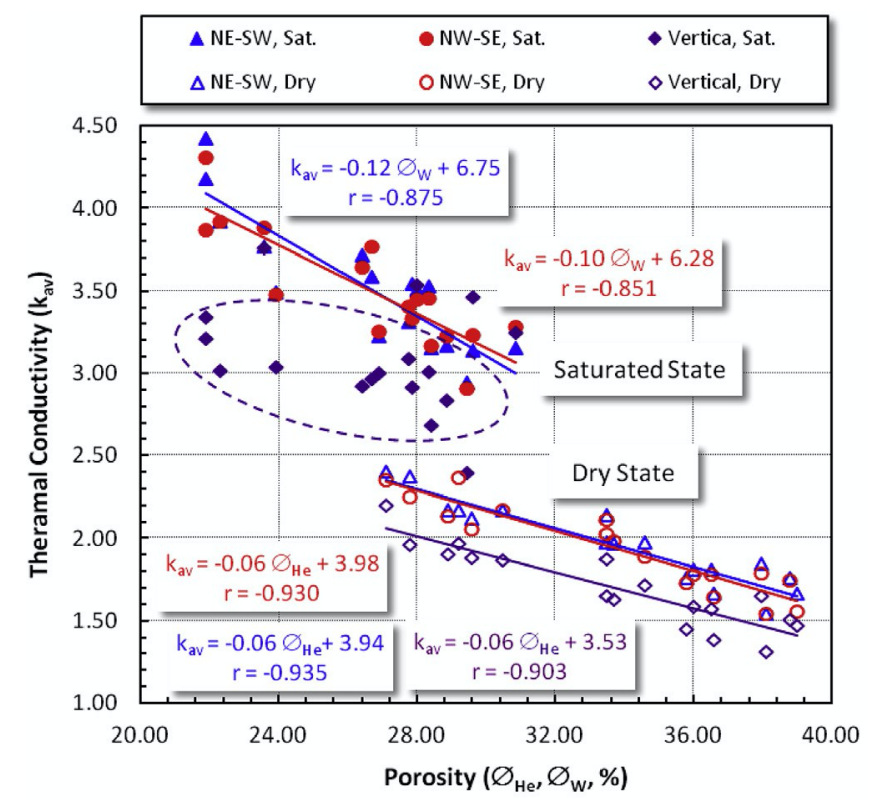

(A)

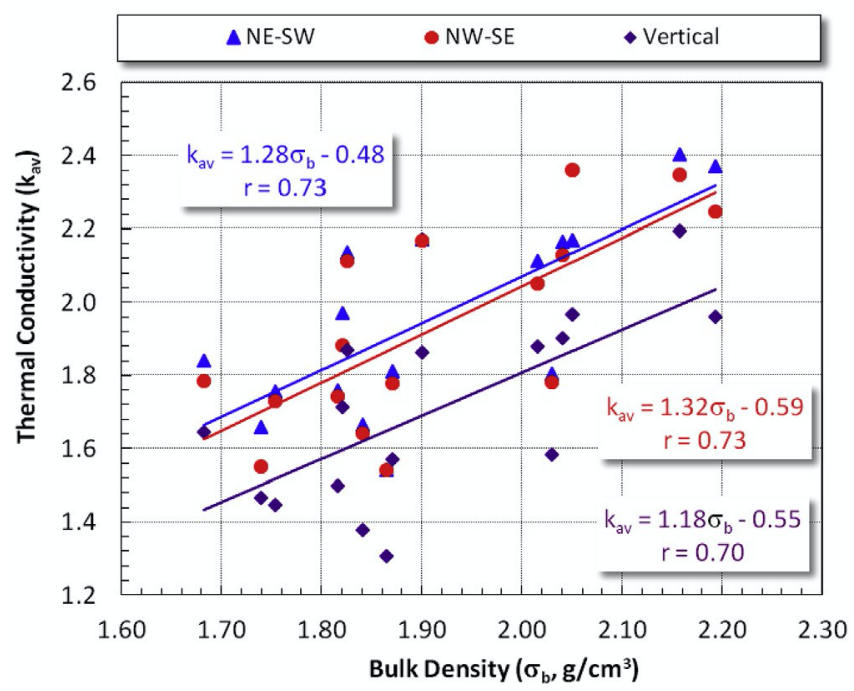

(B)

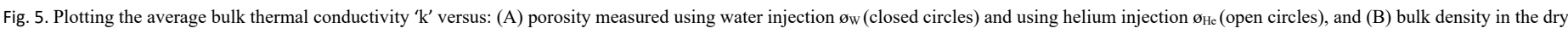
state, along the measured profiles through the different directions of the studied samples.

sented by a general linear relationship in the different profiles following a simple empirical equation applicable for the overall samples.

$\mathrm{k}_{\mathrm{av}} 1 / 4 \mathrm{a}$ Qz p b đr $1 / 40: 883 \pm 0: 035 \mathrm{p}$

(9)

Where, $\mathrm{a}$ is a multiplication factor equals to $0.086 \pm 0.002$, and $\mathrm{b}$ is a constant value equals to $6.22 \pm 0.13$.

5.3.1.3. Relationship between the clay content and $\mathrm{k}_{\mathrm{av}}$. The bulk thermal conductivity is also dependant on the clay content as a secondary component of the present samples. The impact of the clay content on the bulk thermal conductivity can be represented by an inverse linear relationship; the average bulk thermal conductivity decreases with increasing clay content (Fig. 6B). Out of the total 19 samples, it is just 8 samples (no. 3, 7, 10, 12, 13, 16, 17, 18) that follow a best fit line of high reliability whereas the other samples are scattered. Scattering of samples may be attributed to the pore- and petro-fabrics. Processing the overall data obtained in the different profiles result in an equation applicable for the bulk samples as follows:

$k_{a v} 1 / 4$ a b Clay $ð r 1 / 40: 932 \pm 0: 013 p$

Where, a is a constant equals to $2.37 \pm 0.16$, and $\mathrm{b}$ is a multiplication factor equals to $0.117 \pm 0.002$. 
5.3.1.4. Relationship between 1 and kav. Based on the anisotropy scale that proposed by Nabawy and El-Hariri (2008) and Nabawy et al. (2009b), the petro-fabric of the studied samples which was declared by the measured bulk thermal conductivity in the dry state shows a slight foliation ( $\mathrm{F}$ varies from 1.06 to 1.21 of average $1.14 \pm 0.053$ ), negligible lineation ( $\mathrm{L}$ varies from 1.00 to 1.09 of av. $1.025 \pm 0.027$ ) and slight anisotropy (I varies from 1.10 to 1.22 of average $1.17 \pm 0.050$ ) (Table 2). This is an indication for the main depositional flattened fabrics due to the primary load pressure and compaction by depth.

The slight thermal anisotropy is mostly due to their slight foliation (Fig. 7A, $\mathrm{r} 1 / 40.92$ ), whereas the thermal lineation has neither contribution to I of the present rocks nor the thermal foliation.

F 1/4 0:961p 0:019 đr 1/4 0:92p

The vertical tracing of the bulk thermal conductivity and some other petrophysical parameters and mineral composition, showed that the ' $\mathrm{k}$ ' is mainly dependant on the measured pore volume ' $\varnothing$ '

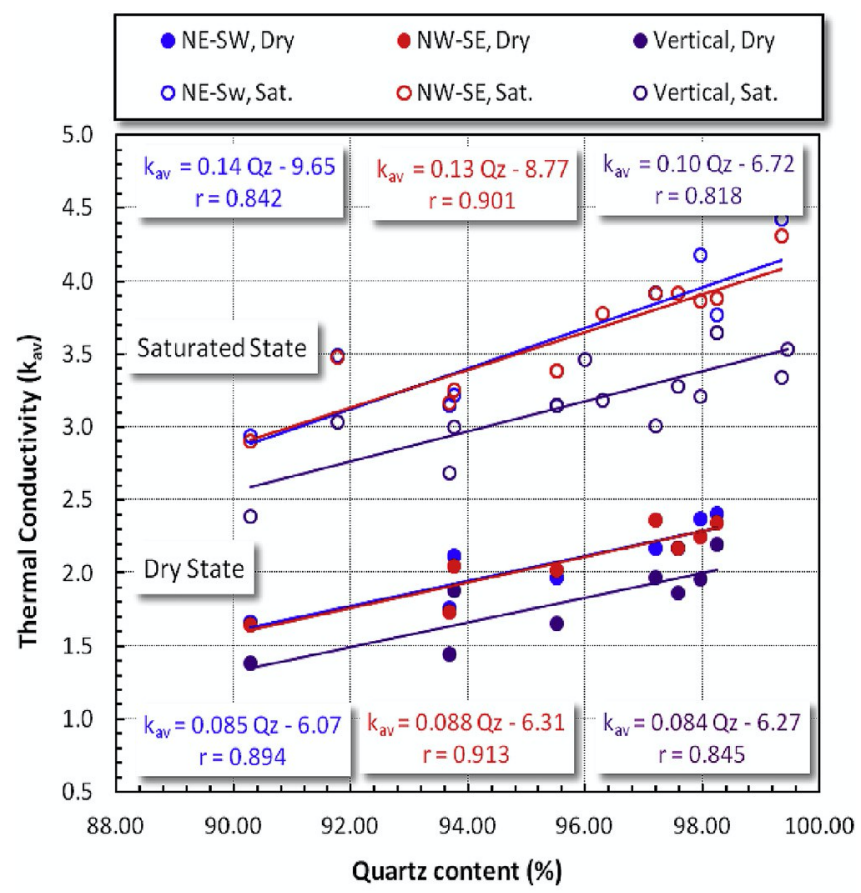

(A)

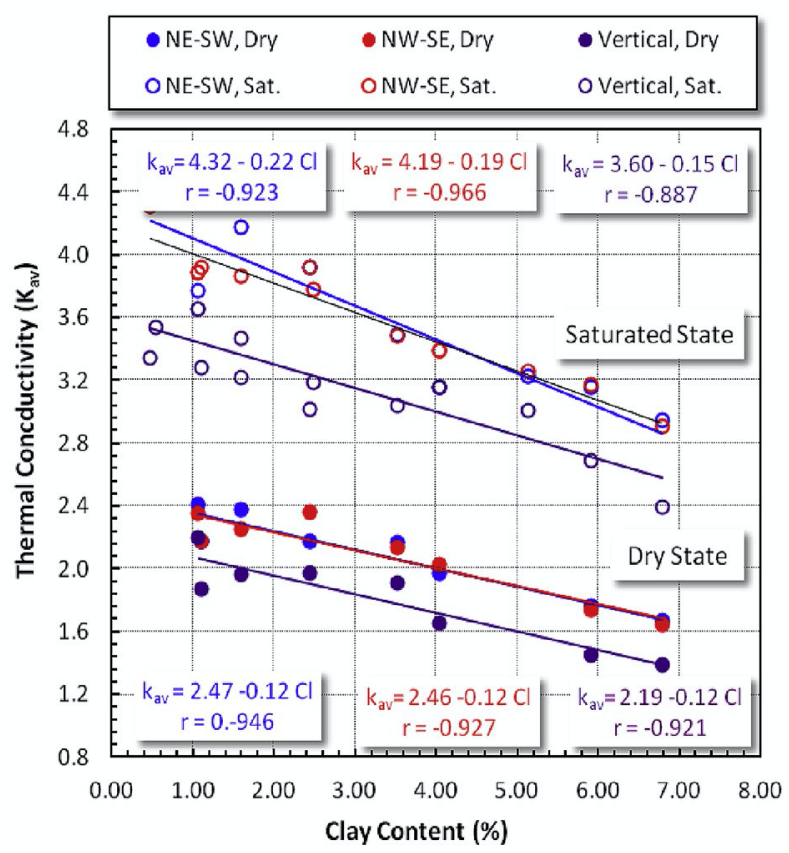

(B) 


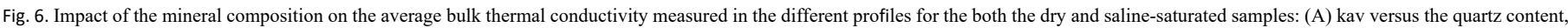
and (B) kav versus the clay content.

through the entire section, on the clay content and the quartz content (Fig. 9). Moreover, it is noticed that the mean ' $\mathrm{k}$ ' in the three profiles increase and decrease simultaneously with a little shift away from each other.

\subsubsection{Saline-saturated state}

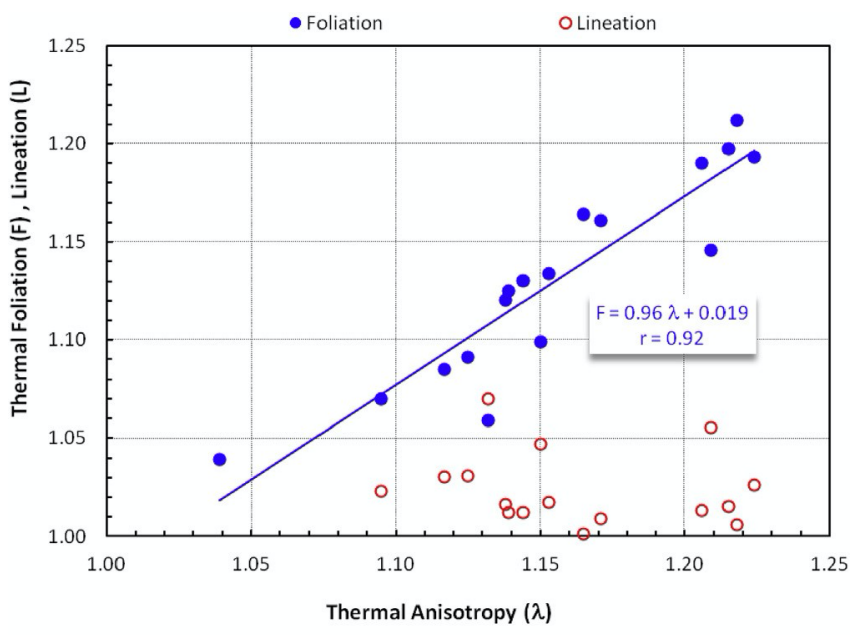

(A)

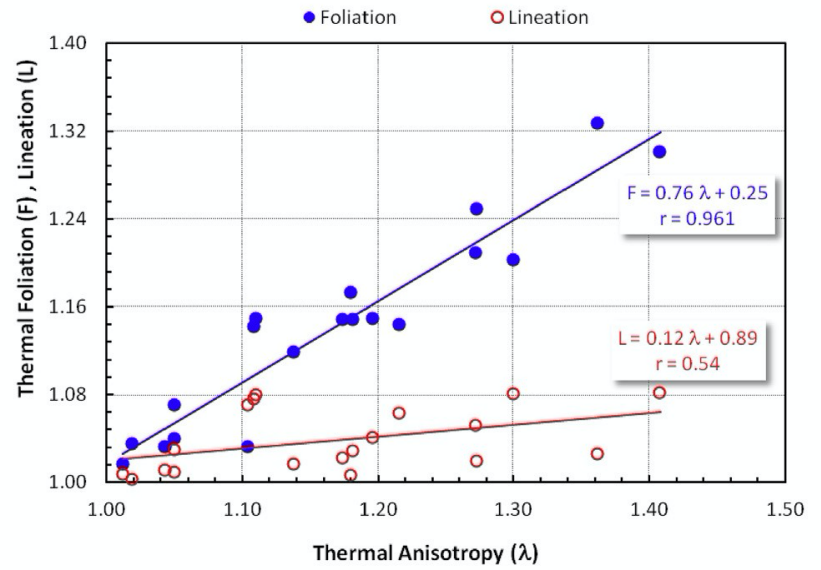

(B)
The ' $\mathrm{k}$ ' values of the saline-saturated plugs $(50 \mathrm{kppm} \mathrm{NaCl})$ 


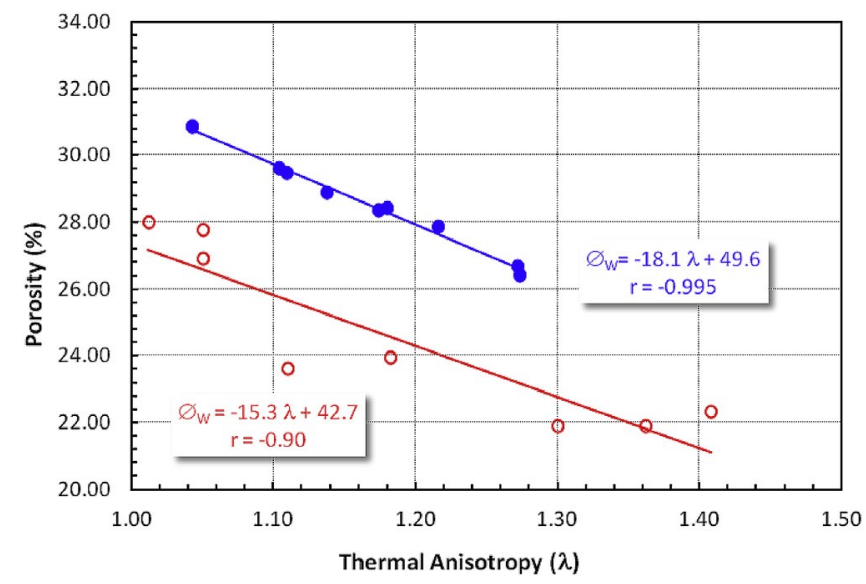

Fig. 8. Plotting the thermal anisotropy ' "' degree versus porosity of the saturated sandstone samples.

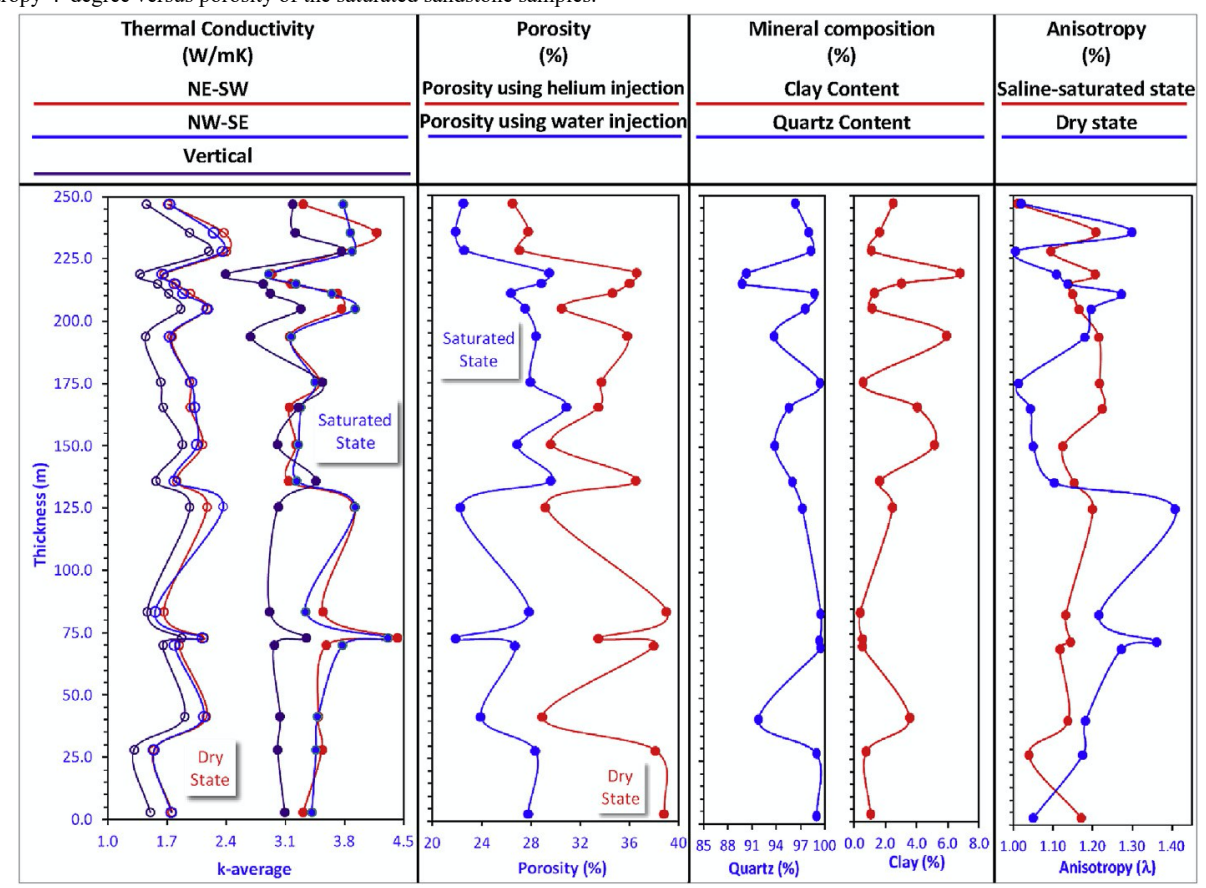

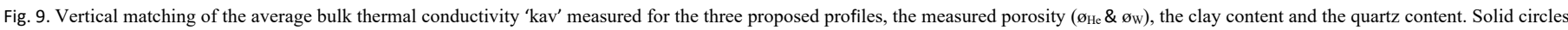
represent the studied samples in saturated state, whereas open circles for samples in dry state.

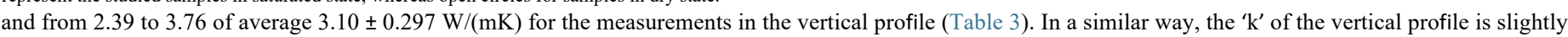
lower than that of the other two horizontal profiles which are more or less similar.

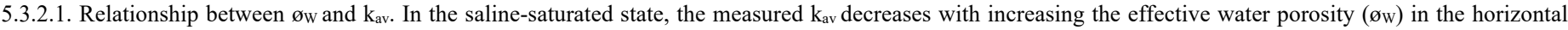

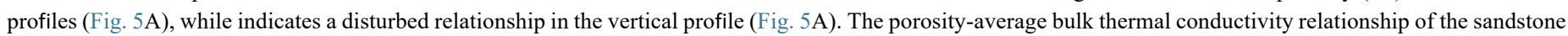
samples could be presented by the following equation.

$\mathrm{k}_{\mathrm{av}} 1 / 4 \mathrm{~b}$ a $\emptyset$ or $1 / 40: 863 \pm 0: 017 \mathrm{p}$

Where, $\mathrm{a}$ is a multiplication factor equals to $0.113 \pm 0.012$, and $\mathrm{b}$ is a constant factor equals to $6.52 \pm 0.33$.

5.3.2.2. Relationship between the quartz content and $\mathrm{k}_{\mathrm{av}}$. The impact of mineral composition on the measured conductivity can be traced through plotting the mineral composition including the quartz and clay content versus the average measured conductivity as shown in Fig. 6.

The impact of the quartz content on the measured average bulk thermal conductivity ( $\left.k_{\mathrm{av}}\right)$ is in contrast to the effect of the clay content. It can be presented by a linear relationship for the salinesaturated sandstone samples (Fig. 6A) in the different profiles following a simple empirical equation. 
Where, ao is a multiplication factor equals to $0.124 \pm 0.019$, and bo is a constant equals to $8.38 \pm 1.50$.

The quartz-bulk thermal conductivity model covers $70 \%$ of the studied samples in the vertical relationship with the highest reliability for samples taken in the NEeSW direction.

5.3.2.3. Relationship between the clay content and $\mathrm{k}_{\mathrm{av}}$. The effect of the clay content can be presented in a linear relationship; the average bulk thermal conductivity is inversely related to the clay content (Fig. 6B). The effect of the clay content on the measured kavo in the different profiles can be represented by the following simple empirical equation.

$\mathrm{k}_{\mathrm{av}} 1 / 4 \mathrm{a}$ b clay or $1 / 40: 925 \pm 0: 040 \mathrm{p}$

Where, $\mathrm{k}_{\mathrm{av}}$ is the average bulk thermal conductivity for the different direction of each sample.

a is a constant equals to $4.04 \pm 0.38$, and $\mathrm{b}$ is a multiplication factor equals to $0.182 \pm 0.035$.

The obtained model satisfies about $66 \%$ of the studied samples in with the lowest reliability in the vertical direction as the highest reliability was assigned to the samples taken in the NEeSW direction.

5.3.2.4. Relationship between 1 and $\mathrm{k}_{\mathrm{av}}$. Similar to the dry case, the thermal 3-D fabric of the studied saline-saturated samples have slight foliation (1.0e1.33, av. $1.13 \pm 0.091)$, negligible lineation $(1.00 \mathrm{e} 1.08$, av. $1.03 \pm 0.028)$ and slight thermal anisotropy $(1.01 \mathrm{e} 1.41$, av. $1.16 \pm 0.116)$, which ensures a slight effect of the load pressure and compaction by increasing depth.

For the same thermal anisotropy ' $I$ ' values, the thermal foliation ' $F$ ' values are higher than the thermal lineation 'L' values (Fig. 7B), i.e. the thermal anisotropy of the saturated samples is mainly attributed to their slight foliation in a very good direct proportional relationship ( $\mathrm{r} 1 / 40.96)$, whereas the thermal lineation has relatively low contribution to I of the present rocks $(\mathrm{r} 1 / 40.54)$.

F 1/4 0:761p 0:25 đr $1 / 40: 96 \mathrm{p}$

L $1 / 40: 121 p 0: 89 \quad$ or $1 / 40: 54 p$

For the present saturated case, it is declared that increasing the effective porosity decreases the 'l' (Fig. 8). It is noticed that the behaviour of the (øI) can be distinguished into two groups of samples of different porosity values but have the same trend (Fig. 8). From the mentioned figure it is stated that, for the same porosity value, we have two different anisotropy values, which may be raised up from the grain shape anisotropy.

The vertical tracing of the bulk thermal conductivity and the effective porosity as well as the quartz and clay content, showed that ' $\mathrm{k}$ ' increases with decreasing the effective porosity and the clay content while increases with increasing the quartz content (Fig. 9).

\section{General discussion}

The Nubia sandstone samples are differentiated into two main facies; quartz arenite (quartz content $95.5 \%$ and kaolinite $5.92 \%$ ), and ferruginous quartz arenite (quartz $89.7 \%$, kaolinite $6.79 \%$, iron oxides $3.36 \%$ and rare carbonate $1.22 \%$, Table-1). The bulk thermal conductivity of the quartz sand is higher than the clay minerals (Cermak and Rybach, 1982; Vasseur et al., 1995).

The measured bulk thermal conductivity ' $\mathrm{k}$ ' of the nubia samples, in general, is mostly controlled by the pore volume and orientation (pore-fabric), mineral composition and the micro structure (petro-fabric).

The petrophysical properties of the studied rocks are due to their pore- and petro-fabrics properties (Nabawy, 2015). For the present samples, ' $\mathrm{k}$ ' is mostly controlled by the pore- and petrofabrics as well as their degree of anisotropism.

\subsection{Pore volume effect (pore-fabric effect)}

The pore volume is the main factor reducing the bulk thermal conductivity where ' $\mathrm{kav}$ ' of the rock matrix forming the rock solid phase is much greater than that of the air filling the pore phase.

kair $<$ silica cement where $\mathrm{k}_{\text {quartz }} \mathrm{k}_{4}^{1 / 4} 3.31 \mathrm{e} 10.17 \mathrm{~W} /(\mathrm{mK})$,

$\mathrm{k}_{\text {silica }} 1 / 41.36 \mathrm{e} 2.07 \mathrm{~W} /(\mathrm{mK})$, and $\mathrm{k}_{\text {air }} 1 / 40.0257 \mathrm{~W} /(\mathrm{mK})$ (Clauser and Huegens, 1995)

For the dry state, the high reliability in the dry state ( $\mathrm{r} 0.90$, Fig. $5 \mathrm{~A})$ is due to the inverse proportional dependence of ' $\mathrm{k}_{\mathrm{av}}$ ' on porosity. 
The bulk density ' $\mathrm{s}_{\mathrm{b}}$ ', as a proxy for both the grain density and the pore volume, has a good direct proportional relationship to the average bulk thermal conductivity ( $\mathrm{r} 1 / 40.72$, Fig. $5 \mathrm{~B})$. The relatively low reliability of the ' $\mathrm{kav}-\mathrm{S}_{\mathrm{b}}$ ' relationship can be attributed to the low density values with high single crystal thermal conductivity (Huenges, 1997). The sandstone samples of the present study are composed mostly of quartz (cemented by silica cement with high porosity ( $\varnothing_{\mathrm{He}}$ $27.1 \%$ ) and low density values $\left(\mathrm{S}_{\mathrm{b}} 2.19 \mathrm{~g} / \mathrm{cm}^{3}\right)($ Table-1), i.e. the present samples follow the high signal crystal thermal conductivity and low density model of Huenges (1997).

The reliability of the obtained ' $\mathrm{kav}_{-} \varnothing$ ' is more disturbed in the saline-saturated state than that of the dry state (Fig. 5A) with higher ' $\mathrm{k}$ ' values measured due to the high porosity of the Nubia sandstone (average $\varnothing_{\mathrm{He}} 1 / 433.7 \%$ ).

In other words, two main fabrics (pore- and petro-fabrics) control the bulk thermal conductivity anisotropy. These fabrics control the overall thermal anisotropy in the saline saturated state due to injecting a brine of relatively higher bulk thermal conductivity than the air which has lower $\mathrm{k}_{\text {av }}$.

\subsection{Effect of the mineral composition on $\mathrm{k}_{\mathrm{av}}$ (petro-fabric effect)}

For the dry state, increasing the clay content as a main mineral constituent of the bulk rock sample, takes the place of the quartz content resulted in decreasing the bulk thermal conductivity of the sandstone samples ( $\left.\mathrm{k}_{\text {clay }}<\mathrm{k}_{\text {quartz }}\right)$.

On the other side, injecting the saline (in the saline saturated state) into the micro pores in between the kaolinite booklets and the quartz grains declared the presence of subsidiary micro fissures and pore fabric parallel to the main petro-fabric of the studied samples. So, as we see in Fig. 6, the reliability of the mineral compositionbulk thermal conductivity relationship increases for ' $\mathrm{k}_{\mathrm{av}}$ ' measured perpendicular to the bedding plane which declare another subsidiary vertical micro cracks and pore system going parallel to the grains skeleton. The introduced models have the highest reliability in the saline-saturated state through the NWeSE direction which ensures alignment of the pore fabric in this direction with the least number of samples follows the NEeSW which is the main trend of the petro-fabric alignment. The highest ' $\mathrm{k}_{\mathrm{av}}$ ' values in the saline-saturated state were measured mostly for the NWeSE profile (Fig. 9). In contrast, the highest ' $\mathrm{k}_{\mathrm{av}}$ ' values for the dry state was measured mostly through the NEeSW profile which again ensures different alignment of the pore- and petro-fabrics of the studied samples (Fig. 9). Shifting the curve of the ' $\mathrm{k}_{\mathrm{av}}$ ' for the vertical direction away from the others measured in the horizontal profiles, especially in the saturated state, ensures the presence of flattened pore fabric.

The vertical tracing of the bulk thermal conductivity, pore volume and the mineral composition in both the dry and saturated states (Fig. 9) ensured that the ' $\mathrm{k}$ ' is mostly reduced by increasing the pore volume and clay content through the entire section, and by increasing the quartz content.

In the dry state, the petro-fabric orientation is the main control for the bulk thermal conductivity, whereas in the saline state both the pore- and petro-fabrics control the overall thermal anisotropy.

\subsection{Effect of anisotropism}

The presence of slightly flattened pore fabric is due to the overload pressure with increasing depth, with the maximum axis within the horizontal bedding plane led to a relatively low average bulk thermal conductivity ' $k$ av' in the vertical direction and relatively high ' $k$ av' measured for the horizontal profiles in both the dry and saline saturated cases.

Increasing the effective porosity decreases I of the salinesaturated rock samples (r 0.86, Fig. 8), can be attributed to more spreading for the saline inside the pore space giving rise to a case of equilibrium between the thermal anisotropy of the petrofabric and the pore-fabric spaces filled with the saline $\left(\mathrm{k}_{\mathrm{saline}}\left(50_{\mathrm{kppm}}\right)^{1 / 4} 0.59 \mathrm{~W} /(\mathrm{mK})\right.$ at $15 \mathrm{C}$, Sharqawy et al., 2010).

kair $<$ saline $<$ matrix

Therefore a question to be answered, do the petro- and porefabric elongations have the same trend?

Nabawy et al. (2009b) mentioned that the petro-fabric elongation of the Nubia sandstone in south Egypt is aligned to the NEeSW direction, whereas the pore fabric seems to be formed in a direction $60 \mathrm{e} 90$ from the petro-fabric elongation. On the other side, the relatively high disturbance of the mentioned relationship in the vertical direction ( $\mathrm{r} 1 / 4 \mathrm{e}$ 0.34) may be attributed to the presence of some vertical joints, fractures and subsidiary pore system aligned in the vertical direction. The fractures and joints can be traced on both the 'field' and micro 'Lab' scales (Fig. 3C).

Another explanation may be attributed to the invasion ability of the applied fluid for assigning the pore volume. The water injection was appreciated for measuring porosity of the saline-saturated samples, where the water volume is a good indicator for the pore volume shared in the bulk thermal conductivity after saline injection. On the other side, helium can invade into smaller micro cracks down to $10 \mathrm{hm}$, so the helium injection was appreciated to measure the pore volume of the dry samples.

The measured ' $\varnothing_{\mathrm{He}}$ ' is greater than the water porosity ' ${ }_{\mathrm{W}}$ ', due to the helium ability to invade into much smaller pore size than the water. The mentioned difference varies from 2.6 to $11.6 \%$ for the different samples which may be attributed to the presence of micro scale cracks as indicated by Nabawy et al. (2009a \& 2009b). These micro cracks and fissures 'subsidiary pore fabric' which can't be invaded by saline injection, are still acting as dry cracks filled with air even after injecting the saline. Therefore, two fabric types act on the bulk thermal conductivity in the saline-saturated state; namely they are the main petro-fabric and the main saline-saturated porefabric. The inability of the saline to invade the subsidiary pore fabric in the saline-saturated state led to less reliability for the ' $\varnothing_{\mathrm{w}} \mathrm{e} \mathrm{k}_{\mathrm{av}}$ ' relationship.

It is interested to mention that, no relationship can be assigned between ' $\varnothing$ ' and both ' $\mathrm{k}_{\mathrm{av}}$ ' and ' 1 ' can be noticed for the dry samples ( $\left.\mathrm{r} 1 / 40.081\right)$. This may lead to a conclusion that, the petro-fabric of the studied samples is not well defined in the dry state and that the mentioned fabric has been declared on saline injection with reliable relationships. On the other side, the pore volume has a reducing effect on the measured ' 1 ' ( $\mathrm{r} 0.90$ ) for the salinesaturated samples.

From the former discussion, it may be stated that, two petrofabrics as well as two pore fabrics are established as main and subsidiary fabrics. These fabrics are thought to have different orientations. For the dry state, it is only the main and subsidiary petrofabrics that are working diminishing each other giving rise to unreliable relationship between the ' $\mathrm{k}_{\mathrm{av}}$ ' and $ø$. For the salinesaturated state, the bulk thermal conductivity fabric has been partially declared due to the effect of the main pore fabric that is going parallel to the main petro-fabric of the studied samples. The partial fabric enhancement may be attributed to presence of another subsidiary pore fabric going in a direction different from that of the main petro-fabric.

The presence of micro cracks and few quartz grains having wavy extinction is a good indication for tectonism which was not intensive enough to give rise to a dominant lineated bulk thermal conductivity fabric, where the flattened fabrics are still the most dominated fabrics. 
The slight anisotropy of the dry samples is mostly attributed to their slight foliation ' $\mathrm{F}$ ' in a direct proportional relationship (Fig. 7A, $\mathrm{r} 1 / 40.92)$, whereas the thermal lineation ' $\mathrm{L}$ ' has no contribution to ' $\mathrm{A}$ ' $(\mathrm{r}<0.2)$. For the saline-saturated state, the contribution of the foliation to the bulk thermal anisotropy is ensured again $(\mathrm{r} 1 / 40.96$, Fig. 7B). In contrast to the dry state samples, slight contribution of the thermal lineation to the bulk anisotropy ( $1 \frac{1}{4} 0.54$, Fig. $\left.7 \mathrm{~B}\right)$ came to the action for the salinesaturated state. This can be attributed to the higher $\mathrm{k}_{\mathrm{av}}$ of the saturating saline than the $\mathrm{k}_{\mathrm{av}}$ of the saturating air in the dry state. The present state, ensures that the main porefabric is aligned in a direction different from the main petrofabric and while the subsidiary one is going parallel to the petrofabric causing a slight sharing in the bulk thermal anisotropy 'l' for the saline-saturated state.

Differentiating the studied samples into two groups on plotting ø versus I in the saline saturated state (Fig. 8) indicates two different thermal anisotropy trends raised up from the pore- and petro-anisotropy. A group has both the pore- and petro-fabrics aligned parallel to each other and the second has two fabrics intersecting each other, where the aligned fabrics support the net bulk thermal fabric, whereas the intersecting fabrics diminish the thermal fabric of each other.

\subsection{Effect of overload pressure on the measured parameters}

A comparison between the measured two sets of bulk thermal conductivity plotted against height in both the dry and saturated state (Fig. 9) shows that two regimes of thermal evolution can be distinguished. The first part, where the shape of the two sets is conserved (0e130 $\mathrm{m} \& 172 \mathrm{e} 225 \mathrm{~m}$ ), which can be attributed to the physical behaviour of rock samples having main pore-fabric aligned together with the main petro-fabric. In the second part, the shape of the vertical plot is changed with height (130.0e172.0, the top part of Abu Simbel Formation), this behaviour can be attributed to subsidiary pore fabric due to the regional thrust faulting that followed the Abu Simbel deposition. This structural thrusting enhanced the main pore fabric of the upper parts of Abu Simbel Formation. Another faulting event has affected the top parts of Kesiena Formation $(224.0 \mathrm{e} 250.0 \mathrm{~m})$.

Concerning porosity ' He' $_{\mathrm{He}}$ measured using the helium injection; it increases downward with increasing depth. This systematic decreasing has to be inversely attributed to increasing the clay content, which decreases downward, rather than effect of overload pressure.

On the other side, slight or negligible over load pressure effect may be noticed controlling the thermal conductivity values of the studied facies with increasing depth, where the pore- and petrofabrics anisotropy increases downward with the highest values recorded for Abu Simbel Formation (Fig. 9).

\subsection{Modeling of the obtained bulk thermal conductivity}

To model the impact of the pore- and petro-fabrics as well as the mineral composition and porosity on the measured average bulk thermal conductivity of the present sandstone samples, a regression analysis has been applied to the obtained data in both the dry and saline-saturated states. The regression analysis introduced two reliable equations applicable for predicting the average bulk thermal conductivity of sandstone in terms of its mineral composition and porosity.

$\mathrm{k}_{\mathrm{av}}$ 1/4 0:0039Qz 0:0224Cl 0:059 $\emptyset_{\mathrm{He}}$ p 3:54ðr

$1 / 4$ 0:963; error $1 / 4 \pm 0: 13 \%$ p

$\mathrm{k}_{\mathrm{av}: 0} \frac{1}{4}$ 0:022Qz 0:0456Cl 0:069 $\emptyset_{\mathrm{w}}$

p 3:18ðr $1 / 40: 933$; error $1 / 4 \pm 0: 17 \%$ p

Where, $\mathrm{k}_{\mathrm{av}}$ is the average bulk thermal conductivity for the dry samples,

$\mathrm{k}_{\mathrm{av}}$ is the average bulk thermal conductivity for the salinesaturated samples, $\mathrm{Qz}$ is the quartz content, in $\%, \mathrm{Cl}$ is the clay content, in $\%$, $\varnothing_{\mathrm{He}}$ is the porosity value measured using Helium injection, in $\%$, and Øw is the porosity value measured using water injection, in \%,

The present study indicates the dependence of $\mathrm{k}_{\mathrm{av}}$ on porosity and clay content as reducing factors and the quartz content as enhancing factor which is in consistence with the previously published literature (e.g. Plewa, 1976; Cermak and Rybach, 1982; etc...). The proposed model has a very high reliability which enables calculating the average bulk ' $\mathrm{k}$ ' in both the dry and saline-saturated states in a very high precision (Fig. 10). The proposed models have very low uncertainty limit $\pm 0.13 \%$ estimated as an error for the dry state and $\pm 0.17 \%$ estimated as an error for the saline-saturated state.

Though the high reliability of the proposed model, it is recommended to use it as a local model applicable for the Nubia sandstone elsewhere. Further studies on similar sandstones are needed to support the obtained model. 


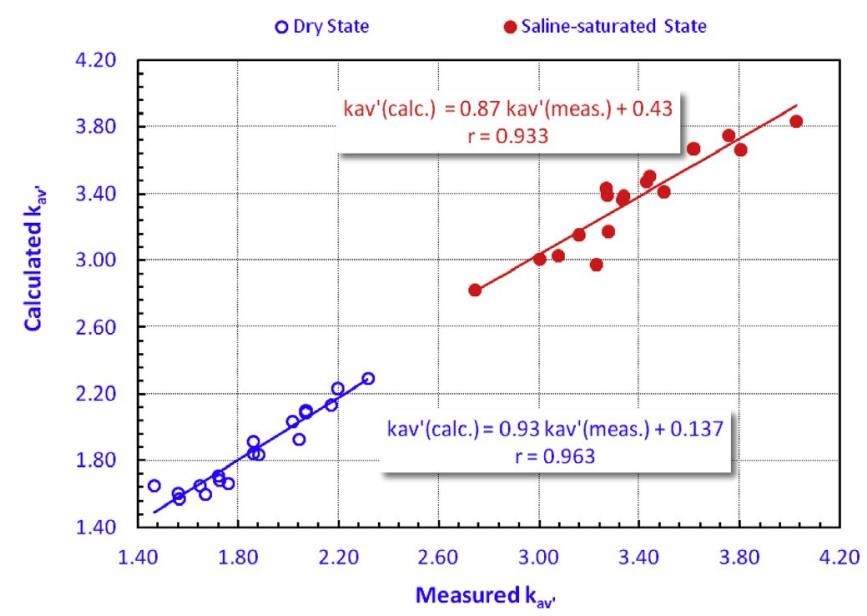

Fig. 10. Plotting the calculated average bulk thermal conductivity versus the measured one in both the dry and saturated states.

\section{Conclusions}

Petrographically, the Nubia sandstone, consist of two microfacies; quartz arenite and ferruginous quartz arenite. Their interstitial pore spaces are described as: intergranular, fracture, vuggy, and intragranular pore spaces. Compaction and pressure solution, cementation by silica cement as well as filling with authigenic kaolinite are the main porosity-reducing diagenetic factors; whereas cement dissolution and fracturing are the main porosityenhancing diagenetic factors. The pore volume and geometry contribution is a key control for the bulk thermal conductivity ' $\mathrm{k}$ '. Thermal properties of the studied samples in the dry and saturated states are controlled primarily by: 1) mineral composition (quartz and clay content); 2) pore volume; 3) saturating fluid (its salinity, type and percentage); and 4) poreand petro-fabrics.

Porosity is the main reducing factor for the bulk thermal conductivity ' $k$ '. The petro-fabric is the main contributor to the slightly flattened thermal fabric in the dry state. The present study reveals that the pore fabric is composed from two pore systems: 1) main system elongated at $60 \mathrm{e} 90$ (fluctuating between the NEeSW and the NWeSE directions) to the petro-fabric; and 2) subsidiary system aligned parallel to the petro-fabric causing acceptable relationship between ' $\mathrm{k}_{\mathrm{av}}$ ' and porosity along the horizontal plain in the saline state.

The slight anisotropy of the present samples is mostly attributed to their slight foliation ' $\mathrm{F}$ '.

The present study introduced a reliable model for calculating the $\mathrm{k}_{\mathrm{av}}$ of the Nubia sandstone in high precision in both the dry and saline-saturated states. Acknowledgment

The authors greatly thank the reviewers for the peer review and good suggestions that reconstructed and enhanced the quality of the data processing and discussion. Great thanks have to be introduced to Prof. Dr. Eriksson, the editor of African Earth Sciences, whose comments and modifications have greatly improved the manuscript.

\section{References}

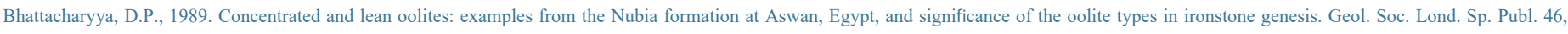
$93 \mathrm{e} 103$.

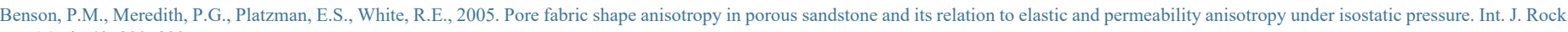
Mech. 42, 890e899.

Bjorkum, P.A., 1996. How important is pressure in causing dissolution of quartz in sandstones. J. Sediment. Res. 66, 147e154.

Bjorkum, P.A., Walderhaug, O., Aase, N.E., 1993. A model for the effect of illitization on porosity and quartz cementation of sandstones. J. Sediment. Res. 63 (6), 1089 e1091.

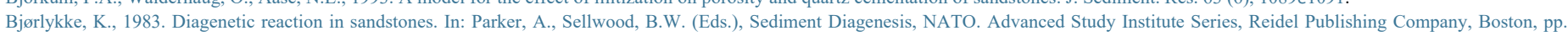
$169 \mathrm{e} 213$.

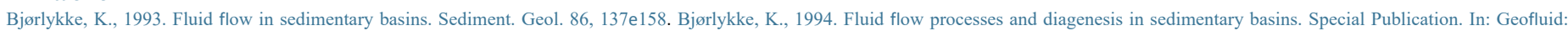
Origin and Evolution of Fluids in Sedimentary Basins. Geological Society, 78, pp. 127e140.

Bjørlykke, K., Ramm, M., Saigal, G.C., 1989. Sandstone diagenesis and porosity modification during basin evolution. Geol. Rundsch. 78 (1), $243 e 268$.

Bjørlykke, K., Høeg, K., 1997. Effects of burial diagenesis on stresses, compaction and fluid flow in sedimentary basins. Mar. Petroleum Geol. 14 (3), $267 e 276$.

Blackwell, J.H., 1954. A Transient-flow method for determination for thermal constants of insulating materials in bulk. J. Appl. Phys. 25, 137e144.

Blackwell, J.H., 1956. The axial-flow error in the thermal-conductivity probe. Can. J. Phys. 34, $412 \mathrm{e} 417$.

Cermak, V., Rybach, L., 1982. In: Physical Properties of Rocks, vol. 1. LandoltBo€rnstein, Springer Verlag, 373 pp.

Choquette, P.W., Pray, L.C., 1970. Geologic nomenclature and classification of porosity in sedimentary carbonates. Bull. Am. Assoc. Petroleum Geol. 54 (2), 207e250.

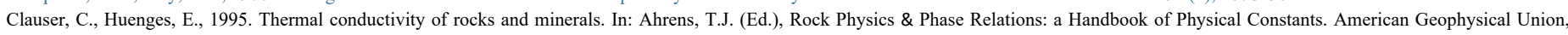
Washington, D.C.. http://dx.doi.org/ 10.1029/RF003p0105

Fuchs, S., Schütz, F., Fo€rster, H.-J., Fo€rster, A., 2013. Evaluation of common mixing models for calculating bulk thermal conductivity of sedimentary rocks: correction charts and new conversion equations. Geothermics 47, 40e 52 .

Hendriks, F., 1988. Evolution of the depositional environments of SE Egypt during the Cretaceous and lower tertiary. Belliner Geowiss Abh 75 (1), $49 \mathrm{e} 82$.

Huenges, E., 1997. Factors controlling the variances of seismic velocity, density, thermal conductivity and heat production of cores from the KTB pilot hole

Geophys. Res. Let. 24 (3), 341 e344.

Issawi, B., 1973. Nubia sandstone type section. Bull. Am. Assoc. Petroleum Geol. 57, 741e745.

Issawi, B., Osman, R.A., 1993. Tectonic-sedimentary synthesis of Paleozoiccretaceous clastics, SW Aswan, Egypt. J. Sedimentol. Soc. Egypt 1, 11 e22. 
Jones, C., Meredith, P.G., 1998. An experimental study of elastic wave propagation anisotropy and permeability anisotropy in an illitic shale, in Eurock 98. Rock Mech. Petroleum Eng. 2,307 e313. Klitzsch, E., 1979. Zur Geologie des Gilf Kebir Gebietes in der Ost Sahara Clauth. Geowiss. Abh 30, 113e132.

Lo, T.W., Coyner, K.B., Toksoz, M.N., 1986. Experimental determination of elastic anisotropy of Berea sandstone, Chicopee shale, and Chelmsford granite. Geophysics 51, 164e171.

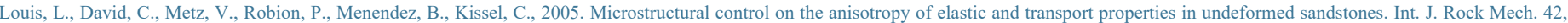
$911 \mathrm{e} 923$.

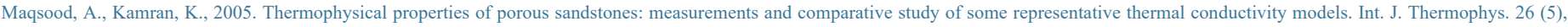
$1617 \mathrm{e} 1632$

McKenna, T.E., Sharp Jr., J.M., Lynch, F.L., 1996. Thermal conductivity of Wilcox and Frio sandstones in south Texas. Gulf of Mexico basin. Bull. Am. Assoc. Pet. Geol. 80 (8), 1203e1215.

Muskat, M., 1937. The Flow of Homogeneous Fluids Through Porous Media, first ed. McGraw-Hill Book Company, Inc. 763pp.

Nabawy, B.S., 2013. Impacts of dolomitization on the petrophysical properties of the Cenomanian El-Halal formation, north Sinai, Egypt. Arab. J. Geosci. 6 (2), 359 e373.

Nabawy, B.S., 2014. Estimating porosity and permeability using digital image analysis (DIA) technique for highly porous sandstones. Arab. J. Geosci. 7 (3), 889 e898.

Nabawy, B.S., 2015. Impacts of the pore- and petro-fabrics on porosity exponent and lithology factor of Archie's equation for carbonate rocks. J. Afr. Earth Sci. $108,101 \mathrm{e} 114$.

Nabawy, B.S., El-Hariri, T.Y., 2008. Electric fabric of Subsurface cretaceous rocks, abu Gharadig basin, western desert, Egypt. J. Afr. Earth Sci. 52 (1e2), 55 e61.

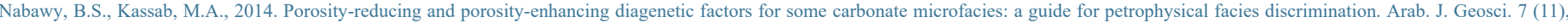
$4523 \mathrm{e} 4539$.

Nabawy, B.S., Geraud, Y., Rochette, P., Nicolas, B., 2009a. Pore-throat characterization in highly porous and permeable sandstones. Bull. Am. Assoc. Pet. Geol. 93 (6), 719 e739.

Nabawy, B.S., Rochette, P., Geraud, Y., 2009b. Petrophysical and magnetic pore network anisotropy of some cretaceous sandstone from Tushka Basin, Egypt. Geophys. J. Int. 177 (1), 43 e61.

Nabawy, B.S., Rochette, P., Yves, Y., 2010. Electric pore fabric of the Nubia sandstones in south Egypt: characterization and modelling. Geophys. J. Int. 183 , 681e694.

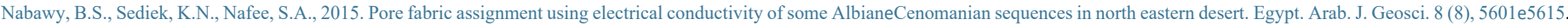

Pettijohn, F.J., Potter, P.E., Siever, R., 1973. Sand and Sandstone. Springer-Verlag, Berlin, 618 pp.

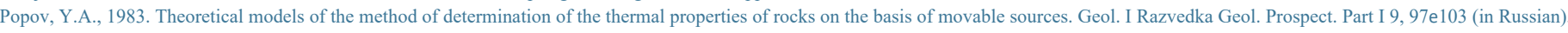

Popov, Y.A., 1984. Theoretical models of the method of determination of the thermal properties of rocks on the basis of movable sources. Geol. I Razvedka Geol.

Prospect. Part II 2, 83e86 (in Russian).

Popov, Y.A., Pribnow, D.F.C., Sass, J.H., Williams, C.F., Burkhardt, H., 1999. Characterization of rock thermal conductivity by high-resolution optical scanning. Geothermics 28 (2), 253 e276.

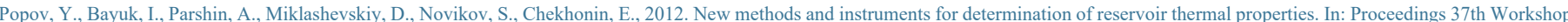
on Geothermal Reservoir Engineering. Stanford University, Stanford, California, 30 Jan-1 Feb. 2012, SGP-TR-194.

Pribnow, D., Umsonst, Th, 1993. Estimation of thermal conductivity from the mineral composition: influence of fabric and anisotropy. Geophys. Res. Lett. 20 (20), $2199 \mathrm{e} 2202$.

Progelhof, R.C., Throne, J.L., Ruetsch, R.R., 1976. Methods for predicting the thermal conductivity of composite systems: a review. Polym. Eng. Sci. 16 (9), 615 e625.

Rasolofosaon, P.N.J., Zinszner, B.E., 2002. Comparison between permeability anisotropy and elastic anisotropy of reservoir rocks. Geophysics $67,230 \mathrm{e} 240$.

Said, R., 1962. Geology of Egypt. Elsevier Pub. Co., Amsterdam, New York, pp. 218 e287.

Sharqawy, M.H., Lienhard, V.J.H., Zubair, S.M., 2010. Thermophysical properties of seawater: a review of existing correlations and data. Desalination Water Treat. 16, 354e380.

Surma, F., Geraud, Y., 2003. Porosity and thermal conductivity of the Soultz-sousForets granite. Pure Appl. Geophys. 160, $1125 \mathrm{e} 1136$.

Tiab, D., Donaldson, E.C., 1996. Petrophysics: Theory and Practice of Measuring Reservoir Rock and Fluid Transport Properties. Gulf Publ. Co., Houston Texas, ISBN 9780123838483.

Vasseur, G., Brigaud, F., Demongodin, L., 1995. Thermal conductivity estimation in sedimentary basins. Tectonophysics $244,167 \mathrm{e} 174$ 